\title{
Offshoring, Exporting, and Jobs
}

\author{
Jose L. Groizard \\ Departament d'Economia Aplicada \\ Universitat de les Illes Balears
}

\author{
Priya Ranjan* \\ Department of Economics \\ University of California, Irvine
}

\author{
Antonio Rodriguez-Lopez \\ Department of Economics \\ University of California, Irvine
}

October 2013

\begin{abstract}
We construct a two-sector model - one producing a homogeneous good and the other producing differentiated goods - with labor market frictions to study the impact of offshoring on intrafirm, intrasectoral, and intersectoral reallocation of jobs, and on the economy-wide unemployment rate. A reduction in the offshoring cost affects intrafirm and intrasectoral reallocation in the differentiated-good sector through a job-relocation effect, a productivity effect, and a competition effect. The key parameters determining the impact of offshoring on reallocation of jobs at various margins as well as on the economy-wide unemployment rate are the elasticity of substitution between inputs and the elasticity of demand for differentiated goods. Allowing differentiated-good firms to export creates an additional channel through which a reduction in the cost of offshoring affects jobs and unemployment. We also show that the implications of a reduction in the cost of trading final goods are different from those of a reduction in the offshoring cost.
\end{abstract}

\section{JEL Classification: F12, F16}

Keywords: heterogeneous firms, offshoring costs, search frictions, unemployment

\footnotetext{
* Corresponding author. Department of Economics, University of California, Irvine. Address: 3151 Social Science Plaza, Irvine, CA 92697-5100, USA. Telephone number: +1 (949) 824-1926. Fax number: +1 (949) 824-2182. E-mail: pranjan@uci.edu.
} 


\section{Introduction}

Offshoring refers to the relocation of a part of the production process abroad either within the firm's boundary or through arm's length trade. Since the relocation of the production process goes hand in hand with the relocation of jobs, it gives rise to the fear - fed by media stories - that there are job losses in the country whose firms engage in offshoring. ${ }^{1}$ Not only has this caused anxiety among the public at large, but politicians in the U.S. (on both sides of the aisle) and Europe have done fear-mongering regarding offshoring. ${ }^{2}$ This has also given rise to calls to throw sand in the wheels of offshoring to stem job losses. However, this simplistic story ignores the various channels through which offshoring can affect jobs. Before implicating offshoring as the main source of job losses, we need to understand its overall employment effects and not just the immediate job-relocation effect. This paper constructs a two-sector theoretical model with labor market frictions to identify the channels through which offshoring affects job flows (at the firm and industry levels) and the economy-wide unemployment rate.

In our set up, one sector produces a homogeneous good using only domestic labor. The other sector has heterogeneous firms producing differentiated goods. The differentiated-good firms use a continuum of intermediate inputs, which are combined using a constant elasticity of substitution (CES) production function. The production of each intermediate input can be either offshored or undertaken using domestic labor, but offshoring is subject to heterogeneous costs à la Grossman and Rossi-Hansberg (2008). There are search frictions in both sectors affecting the hiring of domestic workers. Workers are mobile across sectors but because of differences in search parameters, unemployment rates and wages differ across sectors. The economy-wide unemployment rate depends on both the sectoral unemployment rates as well as on the share of workers in each sector.

We show that a decrease in the variable cost of offshoring affects employment in the differentiatedgood sector not only by affecting employment at the firm level, but also through changes in the number of firms. Following a reduction in the variable cost of offshoring, offshoring firms increase the fraction of inputs they offshore, which reduces their domestic employment. We call this the job-relocation effect. But also, offshoring firms become more productive as a result of lower input costs, which allows them to charge a lower price. Whether the resultant increase in demand for their

\footnotetext{
${ }^{1}$ For example, The Economist (Jan 19th, 2013) says: "But offshoring from West to East has also contributed to job losses in rich countries, especially for the less skilled, yet increasingly for the middle classes too... In a survey by NBC News and the Wall Street Journal in 2010, $86 \%$ of Americans polled said that offshoring of jobs by local firms to low-wage locations was a leading cause of their country's economic problems."

${ }^{2}$ The same article in The Economist above notes: "Barack Obama's presidential campaign last year repeatedly claimed that his rival, Mitt Romney, had sent thousands of jobs overseas when he was working in private equity. Mr Romney, in turn, attacked Chrysler, a car firm, for planning to make Jeeps in China. France's new Socialist government has appointed a minister, Arnaud Montebourg, to resist 'delocalisation'. Germany's chancellor, Angela Merkel, worries publicly about whether the country will still make cars in 20 years' time."
} 
products translates into higher domestic employment depends on two parameters: the elasticity of substitution between differentiated-good varieties and the elasticity of substitution between inputs. We call this the productivity effect of offshoring on employment. Lastly, a decline in the cost of offshoring makes the competitive environment tougher, leading to a reduction in the demand faced by individual firms. We call this last effect the competition effect of offshoring.

For offshoring firms, the job-relocation and competition effects reduce domestic employment, while the productivity effect - assuming the elasticity of substitution between varieties is higher than the elasticity of substitution across inputs - increases domestic employment. Since non-offshoring firms experience only the competition effect, they reduce their employment. A decline in offshoring costs leads to an increase in the mass of offshoring firms, but the impact on the overall mass of firms in the differentiated-good sector is ambiguous. Combining the effects at the intensive and extensive margins, the net effect of a decline in the offshoring cost on employment in the differentiated-good industry depends on two key parameters: the elasticity of substitution between inputs and the elasticity of demand for differentiated goods. ${ }^{3}$ A low value of the former is more conducive to net job creation - a value below 1 implies complementarity between offshored inputs and domestic labor. Similarly, a high value of the latter -implying a greater increase in the demand for differentiated goods following a reduction in offshoring costs - is more likely to lead to net job creation. We provide numerical examples to highlight the key results.

How these employment changes affect the economy-wide rate of unemployment depends on two factors: the degree of search frictions in each sector and the change in the composition of the workforce. If the degree of search frictions is higher in the differentiated-good sector then the unemployment rate is higher there as well. Now, if in response to a decrease in the cost of offshoring there is a decline in employment in the differentiated-good sector - so that workers move to the (lower unemployment) homogeneous-good sector - then the economy-wide unemployment rate would decline. In the opposite case where workers move to the differentiated-good sector, the economy-wide unemployment rate increases.

Our model also allows us to study the implications of changes in search frictions. For example, a decrease in search frictions in the differentiated-good sector makes it cheaper to hire domestic labor in that sector and consequently offshoring declines. Therefore, the impact on firm-level employment is similar to that of an increase in the cost of offshoring with one difference: there is an additional positive effect on the employment of all firms because the marginal cost of production for all differentiated-good firms declines. Regarding the economy-wide unemployment rate, there

\footnotetext{
${ }^{3}$ By extensive margin, we refer to changes in employment due to entry and exit of firms. On the other hand, by intensive margin we mean employment changes due to expansions and contractions of existing firms.
} 
are two forces at work. While the composition of the labor force matters, as was the case when the offshoring cost changed, now the unemployment rate in the differentiated-good sector declines as well, which would tend to reduce the economy-wide unemployment rate.

The model described above does not allow differentiated-good firms to export. However, an important stylized fact in micro-level data is that importing of inputs and exporting go hand in hand in many firms. For example, Bernard, Jensen, and Schott (2009) document that $42 \%$ of the U.S. civilian employment at private firms was in trading firms, while $30 \%$ of the employment was at the firms that do both export and import. As well, Bernard, Jensen, Redding, and Schott (2007) show that $79 \%$ of firms in the U.S. that import also export. In an important extension of our basic model, we show how offshoring can increase exporting and thereby be an important source of job creation for trading firms.

We extend the model to a North-South world where our original country, the North, offshores some inputs to the South and the differentiated-good producers in both countries can export to each other. The South has a comparative advantage in producing inputs and hence, while the two countries are symmetric with respect to exporting, only the North offshores. In this setting it is shown that a decrease in the cost of offshoring makes the Northern firms more productive relative to the Southern firms in both markets. As a consequence, the numbers of entrants and exporting firms increase in the North, which leads to net job creation at the extensive margin - in the absence of exporting opportunities, there is no guarantee of net job creation at the extensive margin. At the intensive margin, in addition to the job relocation, productivity, and competition effects arising from Northern firms' sales to their domestic market, these effects arise as well for Northern firms' export sales. While the job-relocation and productivity effects for export sales are similar to those for domestic sales, the competition effect in the export market is different. In particular, while the competition effect relevant for domestic sales leads to job destruction, the competition effect relevant for exports leads to job creation. This offshoring-induced job creation due to exporting possibilities increases the likelihood that the overall effect of offshoring on differentiated-good sector employment is positive.

The impact on the economy-wide unemployment rate depends again on the composition of the workforce and the extent of search frictions in the two sectors. The extended model also allows us to do comparative statics with respect to the trading cost of differentiated goods. One notable result compared to the case of a change in the offshoring cost is the absence of job-relocation and productivity effects. In fact, we show that a decline in the offshoring cost and a decline in the cost of trading differentiated goods can have opposite effects on the economy-wide unemployment rate. Lastly, the two trading costs interact in significant ways: the impact of a decrease in the cost of 
trading differentiated goods on job flows is larger the smaller the offshoring cost and vice-versa.

Irrespective of its impact on unemployment, offshoring always increases welfare. Intuitively, offshoring always leads to productivity improvements for the economy, which shows up in the form of a decline in the differentiated-good price index and, consequently, in an increase in welfare. Given our simplifying assumption of a representative household which diversifies away labor income risk, everyone gains from offshoring. However, this result needs to be treated with caution because in reality labor income risks are unlikely to be diversified away completely, and therefore, unemployed individuals are necessarily worse off than employed individuals; if offshoring increases unemployment, it necessarily makes some people - the newly unemployed - worse off.

\section{$1.1 \quad$ Related Literature}

Our modeling of offshoring by heterogeneous firms is informed by stylized facts. In our model there is a fixed cost of offshoring, a feature that we share with the workhorse offshoring model of Antràs and Helpman (2004). An implication is that only the most productive firms offshore, which is consistent with the stylized fact that importing firms are on average more productive and larger than purely domestic firms (see, e.g., Bernard, Jensen, Redding, and Schott, 2007 for the U.S.). We go beyond Antràs and Helpman (2004) in postulating a production function with a continuum of inputs with the set of offshored inputs being determined endogenously and responding to changes in offshoring costs. This is consistent with the evidence in Goldberg, Khandelwal, Pavcnik, and Topalova (2010) who find that a decline in input trade costs expands the set of imported intermediate inputs for Indian firms, which then translates into an increase in the number of final products they produce. Similarly, Gopinath and Neiman (2013) show that a large part of the import adjustment in response to a large currency depreciation in Argentina took the form of a decline in the number of imported inputs at the firm level. This channel, which Gopinath and Neiman (2013) call the sub-extensive margin, can explain $45 \%$ of the decline in Argentina's imports, and is also responsible for the decline in firm-level productivity. Hence, their evidence is also supportive of the offshoring productivity effect obtained in our model. ${ }^{4}$

Empirical evidence also suggests that complementarity/substitutability between inputs may be crucial in determining the labor market implications of offshoring. Therefore, we use a CES production function which allows us to study how the impact of offshoring depends on the elasticity of substitution (or complementarity) among inputs. Using data on the U.S. multinationals, Harrison and McMillan (2011) find that when the tasks performed by the subsidiary of a multinational

\footnotetext{
${ }^{4}$ There is further empirical support for the impact of offshoring on firm productivity. For example, Amiti and Konings (2007) (for Indonesia) and Topalova and Khandelwal (2011) (for India) find the positive effect of lower input tariffs on productivity to be much stronger than the effect lower output tariffs.
} 
are complementary to the tasks performed at home, offshoring leads to more job creation in the United States; however, offshoring causes job losses when the tasks performed in the subsidiary are substitutes for the tasks performed at home. This is consistent with our theoretical result that offshoring is more likely to cause job creation via the productivity effect if inputs are complementary.

Our paper is related to the growing literature on the impact of globalization on labor markets with search frictions. Pioneers of this literature are Carl Davidson and Steven Matusz, who in a series of papers study the implications of introducing unemployment arising from labor market frictions in trade models. As discussed in Davidson and Matusz (2004), their work has focused more on the roles of efficiency in job search, the rate of job destruction, and the rate of job turnover in the determination of comparative advantage. Moore and Ranjan (2005) show how trade liberalization in a skill-abundant country can reduce the unemployment of skilled workers and increase the unemployment of unskilled workers. Since each sector employs only one type of labor, there is no intersectoral reallocation of labor. Felbermayr, Prat, and Schmerer (2011) study the impact of a reduction in the cost of trading final goods on unemployment in a one-sector model with firm heterogeneity. Since their model has only one sector, there is no intersectoral reallocation of labor there either. Neither of these papers studies the implications of offshoring on unemployment.

Our structure with a homogeneous-good sector and a differentiated-good sector - with firm heterogeneity in the latter - is similar to the structure of Helpman and Itskhoki (2010), as is the use of a static model of search frictions. One difference in the modeling of labor market frictions is that while wages are determined by multilateral bargaining in the Helpman-Itskhoki model, we use the competitive-search approach of Shimer (1996) and Moen (1997) where firms post wages and workers direct their search. The most important difference, however, is that our main interest lies in studying the implications of offshoring on unemployment, while they study the implications of trade liberalization in final goods. To this end, we use a production function for firms in the differentiated-good sector which uses a continuum of inputs with heterogeneous offshoring costs. As a result, we identify some channels of influence such as the job-relocation effect, the productivity effect, and the domestic- and export-market competition effects, which arise due to the offshoring structure of our model. In the extension with differentiated-good trade we also provide comparative statics with respect to a decrease in the cost of trading final goods and obtain results similar to Helpman-Itskhoki. We also show that a decrease in the offshoring cost can lead to a very different intersectoral reallocation of resources compared to a decrease in the trading cost of final goods.

Mitra and Ranjan (2010) study the impact of offshoring on unemployment in a two-sector model similar to ours where firms in one of the two sectors offshore. Their offshoring structure is much 
simpler, with perfectly competitive firms producing with two inputs, only one of which can be offshored. Our production structure with a continuum of inputs with all of them being potentially offshorable - with the fraction of offshored inputs depending on offshoring costs - is more general. As well, the introduction of firm heterogeneity allows us to obtain the implications of offshoring at both the intensive and extensive margins. Ranjan (2013) studies the role of wage-bargaining institutions in determining the impact of offshoring on unemployment. Neither of these papers has firm heterogeneity and therefore, cannot study the heterogeneous response of firms to a change in the cost of offshoring. Davidson, Matusz, and Shevchenko (2008) also study the implications of offshoring in a job-search model with the focus on the offshoring of high-tech jobs on low- and high-skilled workers' wages, and on overall welfare.

A related recent paper by Egger, Kreickemeier, and Wrona (2013) also studies the implications of offshoring in a model with firm heterogeneity. Their focus is on the implications of offshoring for inequality in the distribution of income, both within and between entrepreneurs and workers. They extend the model to allow for unemployment, which in their setting is driven by fair-wage considerations. Their Cobb-Douglas production function, same as in Antràs and Helpman (2004), restricts the model to the case of unitary elasticity of substitution between domestic labor and offshored inputs. In our set up, unemployment arises due to search friction and our CES production function with a continuum of inputs allows us to study different degrees of substitution and complementarity between domestic labor and offshored inputs. As well, none of the papers on offshoring and unemployment account for the link between offshoring and exporting activities of firms, which is a novel feature of our paper.

The offshoring structure in our model is related to the trade-in-tasks structure of the model of Grossman and Rossi-Hansberg (2008). While Grossman and Rossi-Hansberg (2008) assume perfect complementarity between tasks, we use a CES production function and show how the results depend crucially on the elasticity of substitution between inputs. ${ }^{5}$ Also, Grossman and Rossi-Hansberg (2008) do not have labor market frictions and they do not consider either firm heterogeneity or exporting possibilities. Bernard, Redding, and Schott (2007) address the predictions of final-good trade liberalization on gross job flows in their Heckscher-Ohlin model with Melitz-type firm heterogeneity; however, neither do they have any labor market frictions, nor do they study the impact of offshoring.

There is a growing empirical literature dealing with the impact of offshoring on employment, which is the main concern of our paper. The evidence is mixed. Görg (2011) provides a compre-

\footnotetext{
${ }^{5}$ By assuming perfect complementarity between tasks, Grossman and Rossi-Hansberg (2008) work with the special case in which the offshoring productivity effect is maximum.
} 
hensive survey of this literature. ${ }^{6}$

Note that none of the above papers explicitly takes into account the possibility of offshoring creating jobs through the export channel identified in our theoretical framework. However, the positive effect of offshoring on employment found in many papers is consistent with the job creating effects of offshoring through exporting. There are some papers which look at the impact of exporting on employment without establishing a causal link between offshoring and the exporting activities of a firm. Biscourp and Kramarz (2007) find that exporting has a positive impact on job growth in French firms while importing has a negative effect on job growth. Using firm-level data from the U.S., Davidson and Matusz (2005) find that net exports are positively associated with job creation. Lastly, using a matched employer-employee data from Denmark, Hummels, Jorgensen, Munch, and Xiang (2011) find that exporting is positively associated with employment but offshoring is negatively associated with employment. Our theoretical framework suggests a causal link between offshoring and exporting; that is, it is possible that some of the positive effect of exporting on employment can be ascribed to offshoring by firms.

\section{The Model}

In this section we present our model with labor market frictions, heterogeneous firms, and heterogeneous offshoring costs. The model assumes a country with two sectors: a differentiated-good sector and a homogeneous-good sector. Production in the homogeneous-good sector uses only domestic labor, but heterogeneous firms in the differentiated-good sector can offshore a fraction of their inputs.

We begin by defining preferences and demand, then we discuss our search approach for the labor market, and describe the homogeneous- and differentiated-good sectors, with special attention on differentiated-good firms' offshoring decisions. Lastly, we define the equilibrium of this model and describe how the economy-wide unemployment rate is determined.

\subsection{Preferences and Demand}

The country is populated by a continuum of households in the unit interval. Households' preferences are defined over a continuum of differentiated goods and a homogeneous good. Following Helpman and Itskhoki (2010), we assume that the utility function for the representative household is given by

$$
\mathbb{U}=H+\frac{\eta}{\eta-1} Z^{\frac{\eta-1}{\eta}}
$$

\footnotetext{
${ }^{6}$ See the discussion of following works in Görg (2011): Görg and Hanley (2005) for Ireland, Ibsen, Warzynski, and Westergard-Nielsen (2010) for Denmark, Amiti and Wei (2005) for the U.K., Amiti and Wei (2009) for the U.S., Hijzen and Swaim (2007) for a multi-country study, and Wagner (2011) for Germany.
} 
where $H$ denotes the consumption of the homogeneous good, $Z=\left(\int_{\omega \in \Omega} z^{c}(\omega)^{\frac{\sigma-1}{\sigma}} d \omega\right)^{\frac{\sigma}{\sigma-1}}$ is the CES consumption aggregator of differentiated goods, and $\eta>1$ is the elasticity of demand for $Z(\eta$ governs the substitutability between homogenous and differentiated goods). ${ }^{7}$ In $Z, z^{c}(\omega)$ denotes the consumption of variety $\omega, \Omega$ is the set of differentiated goods available for purchase, and $\sigma>1$ is the elasticity of substitution between differentiated-good varieties. It is assumed that $\sigma>\eta$ so that differentiated-good varieties are better substitutes for each other than for the homogeneous good. The homogeneous good is the numéraire-its price is 1 .

For differentiated goods, the representative household's demand for variety $\omega$ is given by $z^{c}(\omega)=$ $\frac{p(\omega)^{-\sigma}}{P^{1-\sigma}} P Z$, where $p(\omega)$ is the price of variety $\omega, P=\left[\int_{\omega \in \Omega} p(\omega)^{1-\sigma} d \omega\right]^{\frac{1}{1-\sigma}}$ is the price of the CES aggregator $Z$, and hence, $P Z$ is the aggregate spending on differentiated goods. Given the quasilinear utility function in (1), it follows that $Z=P^{-\eta}$, and therefore, the demand for variety $\omega$ can be rewritten as

$$
z^{c}(\omega)=p(\omega)^{-\sigma} P^{\sigma-\eta}
$$

It follows that the representative household spends $p(\omega) z^{c}(\omega)=p(\omega)^{1-\sigma} P^{\sigma-\eta}$ on this variety.

The representative household spends its labor income, $E$, on homogeneous and differentiated goods. Given the quasi-linearity in (1), it follows that amount $E-P Z=E-P^{1-\eta}$ is spent on the homogeneous good. Therefore, the indirect utility function is given by

$$
\mathbb{V}=E+\frac{P^{1-\eta}}{\eta-1}
$$

which is increasing in spending, $E$, and decreasing in the differentiated-good price index, $P$. Given that there is a unit measure of identical households, equation (2) is also the market demand, $E$ is equivalent to the total labor income in the economy, and $P Z$ is the country's total expenditure on differentiated goods.

\subsection{Labor Market and Search Frictions}

As in Helpman and Itskhoki (2010), each household is composed of a fixed supply of $\mathbb{L}$ workers, with each member willing to devote one unit of labor to production activities in either sector. Given that households are located in the unit interval, the total size of the country's workforce is also $\mathbb{L}$. We assume free mobility of workers across sectors.

Labor markets in both sectors are characterized by search frictions. While search frictions are traditionally introduced in a dynamic framework, Helpman and Itskhoki (2010) convincingly showed that the key insights in a model of trade with search frictions can be as easily generated

\footnotetext{
${ }^{7}$ The qualitative results of this paper would be unchanged with a homothetic utility function (however, the algebra becomes tedious). The Appendix in Helpman and Itskhoki (2010) provides an outline of how to handle the case of homothetic utility.
} 
using a static framework, and this is the approach we adopt. In our description of the labor market, the only difference from Helpman and Itskhoki (2010) is in wage setting: while they assume a multilateral-bargaining approach, we use the competitive-search approach pioneered by Shimer (1996) and Moen (1997) where firms post wages and workers direct their search. ${ }^{8}$

Firms post vacancies and wages to attract workers. Higher wages attract more workers, requiring less vacancies for each worker that a firm intends to hire. We assume that each firm $j$ in sector $i$, for $i \in\{H, Z\}$, decides to post a vacancy in a sub-market $i j$. Denote the number of vacancies posted by a firm $j$ in sector $i$ by $V_{i j}$, and the number of applicants attracted to the job by $U_{i j}$. The firm-worker matching function in sub-market $i j$ is given by

$$
M_{i j}\left(U_{i j}, V_{i j}\right)=m_{i} U_{i j}^{\beta} V_{i j}^{1-\beta}
$$

where $\beta \in[0,1]$. We define the job-finding rate of a worker in sub-market $i j$ as

$$
a_{i j}\left(\theta_{i j}\right) \equiv \frac{M_{i j}\left(U_{i j}, V_{i j}\right)}{U_{i j}}=M_{i j}\left(1, \theta_{i j}\right)
$$

where $\theta_{i j} \equiv \frac{V_{i j}}{U_{i j}}$ is the labor market tightness in that sub-market. Given our Cobb-Douglas matching function, it follows that $a_{i j}\left(\theta_{i j}\right) \equiv m_{i} \theta_{i j}^{1-\beta}$. Also, the vacancy-filling rate of a firm in sub-market $i j$ is

$$
q_{i j}\left(\theta_{i j}\right) \equiv \frac{M_{i j}\left(U_{i j}, V_{i j}\right)}{V_{i j}}=M_{i j}\left(\theta_{i j}^{-1}, 1\right)
$$

that is, $q_{i j}\left(\theta_{i j}\right) \equiv m_{i} \theta_{i j}^{-\beta}$ and $a_{i j}\left(\theta_{i j}\right)=q_{i j}\left(\theta_{i j}\right) \theta_{i j}$. In terms of the numéraire good, the wage rate offered by firm $j$ in sector $i$ is $w_{i j}$, and the cost of posting a vacancy in sector $i$ is $\gamma_{i}$.

\subsubsection{The Homogeneous-Good Sector's Problem}

The market for the homogeneous good is perfectly competitive and the production of one unit of the good requires one unit of labor. We assume that there are single-worker firms in this sector. Since the price of the homogeneous good is 1 , the homogeneous-good firm's profit maximization problem is equivalent to the following cost minimization problem:

$$
\min _{w_{H j}, \theta_{H j}}\left\{w_{H j}+\frac{\gamma_{H}}{q_{H j}\left(\theta_{H j}\right)}\right\} \text { s.t. } a_{H j}\left(\theta_{H j}\right) w_{H j} \geq \underline{w},
$$

where the firm chooses the wage to offer, $w_{H j}$, and the tightness in the sub-market, $\theta_{H j}$, so as to minimize its total labor costs. These costs are given by the sum of the wage paid to the worker

\footnotetext{
${ }^{8}$ Since we are working with large firms, if firms choose employment first and then enter into a wage negotiation with workers, firms have an incentive to strategically overhire workers as first pointed out by Stole and Zwiebel (1996). This makes wage determination analytically complicated, involving partial differential equations. The advantage of the wage-posting approach is that since firms post wages and vacancies simultaneously, there is no overhiring effect, which makes the model easy to solve. The results with wage bargaining are qualitatively similar.
} 
and the total recruiting cost, $\gamma_{H} / q_{H j}$ (the firm must post $1 / q_{H j}$ vacancies to fill one job). The constraint in (4) states that the offered wage must be large enough so that the worker's expected income from a job in that sub-market, $a_{H j} w_{H j}$, is no less than the worker's outside opportunity, $\underline{w}$. Since the constraint always binds, the solution to the cost-minimization problem is given by

$$
w_{H j}=\left(\frac{\beta \gamma_{H}}{1-\beta}\right)^{1-\beta} \frac{\underline{\underline{w}}^{\beta}}{m_{H}} \text { and } \theta_{H j}=\frac{(1-\beta) \underline{w}}{\beta \gamma_{H}} .
$$

Note that the solution is independent of $j$ and thus, we can drop the firm subscript $j$.

Since the market is perfectly competitive, the equilibrium value of $\underline{w}$ is determined by the zeroprofit condition: $1=w_{H}+\gamma_{H} / q_{H}\left(\theta_{H}\right)$. Substituting the expressions for $w_{H}$ and $\theta_{H}$ from above into the zero-profit condition we get

$$
\underline{w}=\left[\beta^{\beta}(1-\beta)^{1-\beta} m_{H} \gamma_{H}^{\beta-1}\right]^{\frac{1}{\beta}} .
$$

Lastly, using (6) we rewrite $w_{H}$ and $\theta_{H}$ as a function of the exogenous parameters:

$$
\begin{aligned}
& w_{H}=\beta \\
& \theta_{H}=(1-\beta)^{\frac{1}{\beta}}\left(\frac{m_{H}}{\gamma_{H}}\right)^{\frac{1}{\beta}} .
\end{aligned}
$$

The expression for $w_{H}$ is same as in the Nash bilateral-bargaining case if the worker's bargaining power is $\beta$.

\subsection{Setup in the Differentiated-Good Sector}

\subsubsection{Production}

As in Melitz (2003), firms in the differentiated-good sector are heterogeneous in productivity. The productivity of a producer is denoted by $\varphi$, and the cumulative distribution function of the productivity levels of all differentiated-good firms is given by $G(\varphi)$, with the probability density function denoted by $g(\varphi)$. Each firm must pay a sunk entry cost of $f_{E}$ in units of the homogeneous good, after which it will observe its realization of productivity drawn from $G(\varphi)$.

Each differentiated good is produced using a continuum of inputs in the interval $[0,1]$. Inputs are ordered so that higher indexed inputs have a higher cost of offshoring, therefore, lower indexed inputs are offshored first. If a firm with productivity $\varphi$ offshores its inputs up to $\hat{\alpha}(\varphi)$, where $\hat{\alpha}(\varphi) \in[0,1]$, its production function is given by $z(\varphi)=\varphi Y(\varphi)$, where

$$
Y(\varphi)=\left(\int_{0}^{\hat{\alpha}(\varphi)} y^{*}(\alpha)^{\frac{\rho-1}{\rho}} d \alpha+\int_{\hat{\alpha}(\varphi)}^{1} y(\alpha)^{\frac{\rho-1}{\rho}} d \alpha\right)^{\frac{\rho}{\rho-1}}
$$

is a CES inputs aggregator. In $Y(\varphi),[0, \hat{\alpha}(\varphi)]$ denotes the range of offshored inputs, $y^{*}(\alpha)$ denotes the firm's requirement of foreign input $\alpha, y(\alpha)$ denotes the firm's requirement of domestic input $\alpha$, 
and $\rho \geq 0$ is the elasticity of substitution/complementarity between inputs, which plays a crucial role in our results. ${ }^{9}$ By allowing the degree of complementarity/substitutability across inputs to vary, our approach generalizes the structure of Grossman and Rossi-Hansberg (2008), who focus their analysis on the case of perfect complementarity $(\rho=0)$.

There are fixed and variable costs of offshoring inputs. If the firm with productivity $\varphi$ decides to offshore, so that $\hat{\alpha}(\varphi)>0$, it must pay a fixed cost of $f_{o}$ in units of the homogeneous good. In addition, the firm requires foreign labor to meet variable offshoring costs. The cost of hiring a unit of foreign labor is $w^{*}$. We assume that one unit of foreign labor is not identical to one unit of domestic labor. In particular, to obtain one unit of input $\alpha$, a firm either employs one unit of domestic labor, or $\lambda k(\alpha)>1$ units of foreign labor. That is, $y(\alpha)=\ell$ and $y^{*}(\alpha)=\frac{\ell^{*}}{\lambda k(\alpha)}$, where $\ell$ and $\ell^{*}$ denote, respectively, units of domestic and foreign labor. As in the model of Grossman and Rossi-Hansberg (2008), the term $\lambda k(\alpha)$ accounts for the additional costs of making foreignproduced input $\alpha$ compatible with domestic inputs. It involves a general component, $\lambda$, and an input-specific component, $k(\alpha)$. The inputs are ordered by their offshoring cost so that $k(\alpha)$ is strictly increasing in $\alpha$.

\subsubsection{Profit Maximization}

Each differentiated-good firm decides whether to offshore or not. Having decided to offshore, the firm decides on what fraction of inputs to offshore, how much domestic and foreign labor to hire, what wage to post for domestic workers, and which sub-market to post its vacancies in. We establish the following lemma for a firm with productivity $\varphi$.

Lemma 1. Let $\hat{\alpha}(\varphi)$ be the fraction of inputs offshored by a firm with productivity $\varphi$, and let $L$ and $L^{*}$ denote the total amounts of domestic and foreign labor employed for the production of the composite input $Y(\varphi)$. Then

$$
Y(\varphi)=\left[\kappa(\varphi) L^{* \frac{\rho-1}{\rho}}+v(\varphi) L^{\frac{\rho-1}{\rho}}\right]^{\frac{\rho}{\rho-1}}
$$

where $\kappa(\varphi) \equiv \lambda^{\frac{1-\rho}{\rho}} K[\hat{\alpha}(\varphi)]^{\frac{1}{\rho}}, K[\hat{\alpha}(\varphi)]=\int_{0}^{\hat{\alpha}(\varphi)} k(\alpha)^{1-\rho} d \alpha$, and $v(\varphi) \equiv[1-\hat{\alpha}(\varphi)]^{\frac{1}{\rho}}$.

The profit-maximization problem for a differentiated-good firm with productivity $\varphi$ is

$$
\max _{\hat{\alpha}(\varphi), L, L^{*}, w_{Z}(\varphi), \theta_{Z}(\varphi)}\left\{p(\varphi) \varphi Y(\varphi)-w^{*} L^{*}-\left[w_{Z}(\varphi)+\frac{\gamma_{Z}}{q_{Z}\left[\theta_{Z}(\varphi)\right]}\right] L\right\} \text { s.t. } a_{Z}\left[\theta_{Z}(\varphi)\right] w_{Z}(\varphi) \geq \underline{w},
$$

where $Y(\varphi)$ is given by (10). In the above expression, the total cost of a unit of domestic labor for a firm with productivity $\varphi$ is given by the wage, $w_{Z}(\varphi)$, plus the recruiting cost, $\gamma_{Z} / q_{Z}\left[\theta_{Z}(\varphi)\right]$.

\footnotetext{
${ }^{9}$ Inputs are gross complements if $\rho \in[0,1)$, they are gross substitutes if $\rho>1$, and they are neither substitutes nor complements if $\rho=1(Y(\varphi)$ becomes the Cobb-Douglas function).
} 
Note that the worker's outside opportunity in the constraint in (11) is again $\underline{w}$. This is due to our free-mobility assumption, which implies that workers are indifferent between searching in either sector.

From the maximization problem in (11), note that irrespective of the amount of domestic labor, $L$, that a firm hires, it will always minimize the cost of hiring a unit of domestic labor. That is, the firm solves

$$
\min _{w_{Z}(\varphi), \theta_{Z}(\varphi)}\left\{w_{Z}(\varphi)+\frac{\gamma_{Z}}{q_{Z}\left[\theta_{Z}(\varphi)\right]}\right\} \text { s.t. } a_{Z}\left[\theta_{Z}(\varphi)\right] w_{Z}(\varphi) \geq \underline{w} .
$$

Since the outside opportunity of workers, $\underline{w}$, is predetermined, it is easily verified that $w_{z}(\varphi)$ and $\theta_{Z}(\varphi)$ are independent of $\varphi$. Using (6) we obtain the following solution for $w_{Z}$ and $\theta_{Z}$ :

$$
\begin{aligned}
w_{Z} & =\frac{\beta m_{H}}{m_{Z}}\left(\frac{\gamma_{Z}}{\gamma_{H}}\right)^{1-\beta} \\
\theta_{Z} & =\frac{1}{\gamma_{Z}}\left[\frac{(1-\beta) m_{H}}{\gamma_{H}^{1-\beta}}\right]^{\frac{1}{\beta}} .
\end{aligned}
$$

Let $\hat{w}_{z}$ denote the total cost of a unit of domestic labor; that is, $\hat{w}_{z}=w_{Z}+\gamma_{Z} / q_{Z}\left(\theta_{Z}\right)$. Given that $q_{Z}\left(\theta_{Z}\right)=m_{Z} \theta_{Z}^{-\beta}$, and using equations (13) and (14), it follows that

$$
\hat{w}_{Z}=\frac{m_{H}}{m_{Z}}\left(\frac{\gamma_{Z}}{\gamma_{H}}\right)^{1-\beta} .
$$

Note from (15) that in the special case when the labor market parameters are identical across sectors $\left(m_{H}=m_{Z}, \gamma_{H}=\gamma_{Z}\right)$ then $\hat{w}_{Z}=1$, so that the cost of hiring a unit of labor is identical across the two sectors. More generally, given the parameters governing search frictions in the two sectors $\left(m_{H}, m_{Z}, \gamma_{H}, \gamma_{Z}\right.$, and $\left.\beta\right)$, the labor market outcomes of interest, $w_{H}, \theta_{H}, w_{Z}, \theta_{Z}$, and $\hat{w}_{Z}$, are determined by (7), (8), (13), (14), and (15).

Since the cost of hiring domestic labor in the differentiated-good sector, $\hat{w}_{z}$, is independent of $\varphi$-as is the cost of hiring foreign labor, $w^{*}$ - the differentiated-good firm's profit-maximization problem in (11) yields a standard mark-up pricing over the firm's marginal cost. To obtain the marginal cost for a firm with productivity $\varphi$, we need to know first the cost of a unit of $Y(\varphi)$. Nonoffshoring firms hire only domestic labor: $\hat{\alpha}(\varphi)=0$ and thus equation (10) collapses to $Y(\varphi)=L$ for these firms. Hence, the cost of one unit of $Y(\varphi)$ for non-offshoring firms is simply $\hat{w}_{Z}$. The following lemma shows the value of $\hat{\alpha}(\varphi)$ and the cost of one unit of $Y(\varphi)$ for offshoring firms.

Lemma 2. For offshoring firms $\hat{\alpha}(\varphi)=\hat{\alpha}$ and the cost of one unit of $Y(\varphi)$ is $c(\hat{\alpha}) \hat{w}_{Z}$, where

$$
\begin{aligned}
& \hat{\alpha}=k^{-1}\left(\frac{\hat{w}_{z}}{\lambda w^{*}}\right), \\
& c(\hat{\alpha})=\left[k(\hat{\alpha})^{\rho-1} K(\hat{\alpha})+1-\hat{\alpha}\right]^{\frac{1}{1-\rho}} .
\end{aligned}
$$

For $\hat{\alpha}>0, c(\hat{\alpha}) \in\left(w^{*} / \hat{w}_{z}, 1\right), c^{\prime}(\hat{\alpha})<0$, and $c(\hat{\alpha}) \hat{w}_{z} \in\left(w^{*}, \hat{w}_{z}\right)$. 
Equation (16) simply says that the marginal cost of offshoring input $\hat{\alpha}$, given by $\lambda k(\hat{\alpha}) w^{*}$, equals the cost of producing it using domestic labor, $\hat{w}_{z}$. Therefore, an offshoring firm offshores input $\alpha$ if and only if $\lambda k(\alpha) w^{*} \leq \hat{w}_{z}$. Since $k^{-1 \prime}(\cdot)>0$, a decline in $\lambda$ or $w^{*}$ makes offshoring more attractive and hence $\hat{\alpha}$ increases. ${ }^{10}$ As well, domestic labor market institutions affect the extent of offshoring - any factor that raises $\hat{w}_{z}$ increases $\hat{\alpha}$. The lemma above also shows that all offshoring firms offshore the same fraction of inputs $\hat{\alpha}$. However, larger firms offshore more in absolute terms. ${ }^{11}$

\subsubsection{Pricing}

Since the cost of a unit of $Y(\varphi)$ is $\hat{w}_{z}$ for non-offshoring firms, the marginal cost of producing differentiated goods for a non-offshoring firm with productivity $\varphi$ is $\frac{\hat{w}_{Z}}{\varphi}$. From Lemma 2, the marginal cost for an offshoring firm with productivity $\varphi$ is $\frac{c(\hat{\alpha}) \hat{w}_{Z}}{\varphi}$. The term $c(\hat{\alpha})$ accounts for the Grossman-Rossi-Hansberg offshoring productivity effect: by offshoring a fraction of its inputs, the marginal cost of a firm with productivity $\varphi$ is lower than the firm's marginal cost if it only employs domestic labor, $\frac{c(\hat{\alpha}) \hat{w}_{Z}}{\varphi}<\frac{\hat{w}_{Z}}{\varphi}$.

Given the fixed cost of offshoring, $f_{o}$, there exists an offshoring cutoff productivity level, $\hat{\varphi}_{o}$, such that a firm offshores if and only if its productivity is no less than $\hat{\varphi}_{o}$. Therefore, the price set by a firm with productivity $\varphi$ can be written as

$$
p(\varphi)=\left(\frac{\sigma}{\sigma-1}\right) \frac{c(\hat{\alpha})^{\mathbb{I}\left\{\varphi \geq \hat{\varphi}_{o}\right\}} \hat{w}_{Z}}{\varphi},
$$

where $\mathbb{I}\left\{\varphi \geq \hat{\varphi}_{o}\right\}$ is an indicator function taking the value of 1 if $\varphi \geq \hat{\varphi}_{o}$, and zero otherwise.

Using this price equation and the market demand function for each variety in equation (2), we obtain that this firm's gross profit function (before deducting fixed costs) is given by

$$
\pi(\varphi)=\frac{p(\varphi)^{1-\sigma} P^{\sigma-\eta}}{\sigma}
$$

Note that $p^{\prime}(\varphi)<0$ and $\pi^{\prime}(\varphi)>0$, so that more productive firms charge lower prices and have larger profits.

\footnotetext{
${ }^{10}$ Corner solutions exist if $(i) \lambda k(0) w^{*} \geq \hat{w}_{Z}$, so that $\hat{\alpha}=0$ and domestic firms never offshore, or (ii) $\lambda k(1) w^{*} \leq \hat{w}_{Z}$, so that $\hat{\alpha}=1$ and domestic firms only employ foreign labor. For simplicity, in our analysis we only consider interior solutions.

${ }^{11}$ Gopinath and Neiman (2013) find evidence from Argentina that larger firms offshore a larger fraction of inputs. As in their theoretical model, we can use input-level fixed costs to generate the result that larger firms offshore a greater fraction of inputs. Let us assume that there is a fixed cost, $f_{I}$, associated with the offshoring of input $I$. Now, the firm's indifference condition between offshoring and procuring an input domestically is given by $\lambda k[\hat{\alpha}(\varphi)] w^{*} l(\varphi)+f_{I}=$ $l(\varphi) \hat{w}_{Z}$, where $l(\varphi)$ is the quantity purchased of this particular input, and $\hat{\alpha}(\varphi)$ is the input for which the cost of domestic production (right-hand side) equals the cost of offshoring (left-hand side). We can rewrite the above equation as $k[\hat{\alpha}(\varphi)]=\left[1 /\left(\lambda w^{*}\right)\right]\left[\hat{w}_{Z}-f_{I} / l(\varphi)\right]$. Also, $l^{\prime}(\varphi)>0$ since more productive firms sell more output. Therefore, $\hat{\alpha}(\varphi)$ is increasing in $\varphi$, i.e. $\hat{\alpha}^{\prime}(\varphi)>0$ : more productive firms offshore a greater fraction of inputs. Under this approach, however, the model's tractability is reduced significantly and offshoring affects employment through the same channels we will identify below.
} 


\subsubsection{Cutoff Productivity Levels}

For every producing firm, there is a fixed cost of operation, $f$, in units of the homogeneous good. Hence, besides the cutoff productivity level that separates offshoring and non-offshoring firms, $\hat{\varphi}_{o}$, there exists a cutoff level $\hat{\varphi}$ that determines whether or not a firm produces: firms with productivity levels below $\hat{\varphi}$ do not produce because their gross profits are not large enough to cover the fixed cost of operation. Thus, $\hat{\varphi}$ is defined as the level of productivity such that $\pi(\hat{\varphi})=f$.

Assuming that $\hat{\varphi}<\hat{\varphi}_{o}$, so that there is a set of firms with productivity levels between $\hat{\varphi}$ and $\hat{\varphi}_{o}$ which produce but do not offshore, we get from equation (18) that $p(\hat{\varphi})=\left(\frac{\sigma}{\sigma-1}\right) \frac{\hat{w}_{Z}}{\hat{\varphi}}$. Substituting $p(\hat{\varphi})$ into equation (19) to obtain $\pi(\hat{\varphi})$, we can write the zero-cutoff-profit condition as

$$
P=(\sigma f)^{\frac{1}{\sigma-\eta}}\left[\left(\frac{\sigma}{\sigma-1}\right) \frac{\hat{w}_{Z}}{\hat{\varphi}}\right]^{\frac{\sigma-1}{\sigma-\eta}} .
$$

Moreover, using (20) to substitute for $P$ in equation (19), along with equation (18), we can conveniently rewrite $\pi(\varphi)$ as

$$
\pi(\varphi)=\left(\frac{\varphi}{c(\hat{\alpha})^{\mathbb{I}\left\{\varphi \geq \hat{\varphi}_{o}\right\}} \hat{\varphi}}\right)^{\sigma-1} f
$$

for $\varphi \geq \hat{\varphi}$.

As $\hat{\varphi}_{o}$ separates out non-offshoring and offshoring firms, a firm with productivity $\hat{\varphi}_{o}$ must be indifferent between offshoring and not offshoring. Using equation (21), this indifference condition can be written as

$$
\left(\frac{\hat{\varphi}_{o}}{c(\hat{\alpha}) \hat{\varphi}}\right)^{\sigma-1} f-f-f_{o}=\left(\frac{\hat{\varphi}_{o}}{\hat{\varphi}}\right)^{\sigma-1} f-f
$$

It follows that the relationship between the cutoff productivities $\hat{\varphi}_{o}$ and $\hat{\varphi}$ is given by

$$
\hat{\varphi}_{o}=B \Gamma(\hat{\alpha}) \hat{\varphi}
$$

where $B=\left(\frac{f_{o}}{f}\right)^{\frac{1}{\sigma-1}}$ and

$$
\Gamma(\hat{\alpha})=\left[\frac{c(\hat{\alpha})^{\sigma-1}}{1-c(\hat{\alpha})^{\sigma-1}}\right]^{\frac{1}{\sigma-1}} .
$$

Note that in order for $\hat{\varphi}<\hat{\varphi}_{o}$, we need to satisfy $B \Gamma(\hat{\alpha})>1$, which we assume to be the case (a sufficient condition is $\left.c(1)>\left[f /\left(f_{o}+f\right)\right]^{\frac{1}{\sigma-1}}\right)$. It can be verified that the gap between $\hat{\varphi}$ and $\hat{\varphi}_{o}$ decreases with $\hat{\alpha}$ and $f$, and increases with $f_{o}$.

\subsubsection{Free-Entry Condition and the Mass of Firms}

Every period, a potential firm will enter if the value of entry is no less than the required sunk entry cost, $f_{E}$. The potential entrant knows its productivity only after entry, and hence, the pre-entry 
expected profit for each period is

$$
\Pi \equiv \int_{\hat{\varphi}}^{\hat{\varphi}_{o}}[\pi(\varphi)-f] g(\varphi) d \varphi+\int_{\hat{\varphi}_{o}}^{\infty}\left[\pi(\varphi)-f-f_{o}\right] g(\varphi) d \varphi
$$

At the end of every period, an exogenous death shock hits a fraction $\delta$ of the existing firms, and hence, the value of entry is $\frac{\Pi}{\delta}$. Given unbounded entry, the free-entry condition is then

$$
\frac{\Pi}{\delta}=f_{E} .
$$

The mass of producing firms in the differentiated-good sector, $N$, is composed of non-offshoring firms and offshoring firms. Let $s \in\{n, o\}$ denote offshoring status, with $n$ meaning "not offshoring" and $o$ meaning "offshoring". If $N_{s}$ represents the mass of firms with offshoring status $s$, it must be the case that $N=N_{n}+N_{o}$. In steady state, the firms that die every period due to the exogenous death shock are exactly replaced by successful entrants so that $\delta N_{n}=\left[G\left(\hat{\varphi}_{o}\right)-G(\hat{\varphi})\right] N_{E}$ and $\delta N_{o}=\left[1-G\left(\hat{\varphi}_{o}\right)\right] N_{E}$, where $N_{E}$ denotes the mass of entrants every period. To obtain $N_{n}, N_{o}$, and $N$ in terms of $\hat{w}_{z}, \hat{\alpha}, \hat{\varphi}$ and $\hat{\varphi}_{o}$, we need to obtain an expression for $N_{E}$. Section B.2 in the Appendix derives $N_{E}$ along with market-share expressions for non-offshoring and offshoring firms.

\subsubsection{Employment}

We now turn our attention to the determination of employment in the differentiated-good sector. Offshoring firms demand foreign labor for the inputs in the range $[0, \hat{\alpha}]$ and domestic labor in the range $(\hat{\alpha}, 1]$. On the other hand, non-offshoring firms demand only domestic labor. Let $L_{s}(\varphi)$ denote the demand for domestic labor of a firm with productivity $\varphi$ and offshoring status $s$, for $s \in\{n, o\}$. The following lemma shows the expressions for $L_{n}(\varphi)$ and $L_{o}(\varphi)$.

Lemma 3. The demand for domestic labor of a firm with productivity $\varphi \geq \hat{\varphi}$ and offshoring status $s$, for $s \in\{n, o\}$, is given by

$$
L_{s}(\varphi)= \begin{cases}\frac{(\sigma-1)}{\hat{w}_{Z}}\left(\frac{\varphi}{\hat{\varphi}}\right)^{\sigma-1} f & \text { if } s=n \\ \frac{(1-\hat{\alpha})(\sigma-1)}{c(\hat{\alpha})^{\sigma-\rho} \hat{w}_{Z}}\left(\frac{\varphi}{\hat{\varphi}}\right)^{\sigma-1} f & \text { if } s=o .\end{cases}
$$

We can also obtain an expression for aggregate domestic employment in the differentiated-good sector. Let $\bar{L}_{s}$ denote the average domestic employment of producing firms with offshoring status $s$, so that $\bar{L}_{n}=\int_{\hat{\varphi}}^{\hat{\varphi}_{o}} L_{n}(\varphi) g\left(\varphi \mid \hat{\varphi} \leq \varphi<\hat{\varphi}_{o}\right) d \varphi$ and $\bar{L}_{o}=\int_{\hat{\varphi}_{o}}^{\infty} L_{o}(\varphi) g\left(\varphi \mid \varphi \geq \hat{\varphi}_{o}\right) d \varphi$. The total employment of domestic labor in the differentiated-good sector is then given by $L_{z}=N_{n} \bar{L}_{n}+N_{o} \bar{L}_{o}$, where $N_{n} \bar{L}_{n}$ is the domestic employment of active non-offshoring firms, and $N_{o} \bar{L}_{o}$ is the domestic employment of offshoring firms. Using the expressions for $N_{n}$ and $N_{o}$ from above, we rewrite $L_{z}$ as

$$
L_{Z}=\frac{N_{E}}{\delta}\left[\int_{\hat{\varphi}}^{\hat{\varphi}_{o}} L_{n}(\varphi) g(\varphi) d \varphi+\int_{\hat{\varphi}_{o}}^{\infty} L_{o}(\varphi) g(\varphi) d \varphi\right] .
$$


In the analysis below, we use equations (26) and (27) to understand the different channels through which offshoring costs and labor-market search frictions affect employment in the differentiatedgood sector.

\subsection{Equilibrium and the Unemployment Rate}

Let us now define this model's equilibrium and the economy-wide unemployment rate.

Definition 1. Given $\pi(\varphi)$ and $\Pi$ in (21) and (24), an equilibrium is a 4-tuple $\left(\hat{w}_{z}, \hat{\alpha}, \hat{\varphi}, \hat{\varphi}_{o}\right)$ that solves (15), (16), (22), and (25). The equilibrium exists and is unique. ${ }^{12}$

The economy-wide unemployment rate is a weighted average of sectoral unemployment rates, with the weights given by the share of workers searching in each sector. The sectoral unemployment rates are determined by search friction parameters. In particular, the unemployment rate in sector $i$, for $i \in\{H, Z\}$, is

$$
u_{i}=1-a_{i}\left(\theta_{i}\right)
$$

Recall that $a_{i}\left(\theta_{i}\right) \equiv m_{i} \theta_{i}^{1-\beta}$ is the job-finding rate in sector $i$, with $\theta_{i}$ denoting the sector's labor market tightness. Denote the number of workers who decide to search in sector $i$ by $\mathbb{L}_{i}$, so that

$$
\mathbb{L}=\mathbb{L}_{H}+\mathbb{L}_{Z}
$$

Hence, the economy-wide unemployment rate, $u$, is

$$
u=u_{H} \frac{\mathbb{L}_{H}}{\mathbb{L}}+u_{Z} \frac{\mathbb{L}_{Z}}{\mathbb{L}}
$$

The expression for $u$ is similar to the one derived by Helpman and Itskhoki (2010). As in their model, given that $\mathbb{L}$ is fixed, the economy-wide unemployment rate increases either when more workers search in the sector with the highest unemployment rate or when the sectoral unemployment rate rises in either sector.

For $\mathbb{L}_{Z}$ and $\mathbb{L}_{H}$, note first that it must be the case that $L_{i}=\left(1-u_{i}\right) \mathbb{L}_{i}$ for $i \in\{H, Z\}$, where $L_{i}$ is the amount of labor employed in sector $i$. Therefore

$$
\mathbb{L}_{Z}=\frac{L_{z}}{1-u_{z}}
$$

where $L_{Z}$ is given by (27). $\mathbb{L}_{H}$ is then determined from (29), which then implies that the amount of labor employed in the homogeneous-good sector is calculated as

$$
L_{H}=\left(1-u_{H}\right)\left(\mathbb{L}-\frac{L_{Z}}{1-u_{Z}}\right) .
$$

\footnotetext{
${ }^{12}$ See proof of existence and uniqueness of equilibrium in section B.1 in the Appendix.
} 
Lastly, the aggregate income of workers is given by $E=w_{H} L_{H}+w_{Z} L_{Z}$. Plugging in (32) into the previous equation, and using (28) and the condition $a_{H} w_{H}=a_{Z} w_{Z}=\underline{w}$-ensured by the assumption of free intersectoral mobility of labor - we obtain

$$
E=w_{H} L_{H}+w_{Z} L_{Z}=\underline{w} \underline{L} .
$$

That is, the aggregate labor income of a household - and hence of the entire country - is simply the product of the expected job income for each member of the household, $\underline{w}$, and the number of members of the household, $\mathbb{L}$.

\section{Offshoring Costs, Job Flows, and Unemployment}

In this section we discuss the model's implications for the effects of a change in offshoring costs on firm- and industry-level employment in the differentiated-good sector as well as on the economywide unemployment rate.

Our measures of offshoring costs are the general component of the variable cost of offshoring inputs, $\lambda$, and the fixed cost of offshoring inputs, $f_{o}$. Recall that the offshoring cost of a unit of input $\alpha$ is $\lambda k(\alpha) w^{*}$ for $\alpha \in[0,1]$ (where $k(\alpha)$ is the input-specific component of the offshoring cost), so that a decrease in $\lambda$ implies a proportional decline in the offshoring costs of all inputs. We focus on the impact of a change in $\lambda$, and leave the discussion of a change in $f_{o}$ for section B.3 in the Appendix.

\subsection{Firm-Level Employment Responses}

For an existing firm with productivity $\varphi$ that does not change its offshoring status $s$ after a change in $\lambda$, its labor demand response is entirely accounted for by changes in $L_{s}(\varphi)$, which is defined in (26) in Lemma 3 . Hence, for this type of firms we can look at the elasticity of $L_{s}(\varphi)$ with respect to $\lambda, \zeta_{L_{s}(\varphi), \lambda}$, which is given by

$$
\zeta_{L_{s}(\varphi), \lambda}= \begin{cases}-(\sigma-1) \zeta_{\hat{\varphi}, \lambda} & \text { if } s=n \\ -\frac{\hat{\alpha}}{1-\hat{\alpha}} \zeta_{\hat{\alpha}, \lambda}-(\sigma-\rho) \zeta_{c(\hat{\alpha}), \lambda}-(\sigma-1) \zeta_{\hat{\varphi}, \lambda} & \text { if } s=o,\end{cases}
$$

where $\zeta_{\hat{\varphi}, \lambda}, \zeta_{\hat{\alpha}, \lambda}$, and $\zeta_{c(\hat{\alpha}), \lambda}$ also denote elasticities. The following lemma presents the signs of these elasticities.

Lemma 4. $\zeta_{\hat{\alpha}, \lambda}<0, \zeta_{c(\hat{\alpha}), \lambda}>0, \zeta_{\hat{\varphi}, \lambda}<0, \zeta_{\hat{\varphi}_{o}, \lambda}>0$.

A decline in the variable cost of offshoring leads to a greater fraction of inputs being offshored; that is, $\zeta_{\hat{\alpha}, \lambda}<0$. Since the jobs associated with the production of these inputs are relocated abroad, we use the term "job relocation" to refer to this effect on domestic labor demand. In equation (34) 
the job-relocation effect is given by $-\frac{\hat{\alpha}}{1-\hat{\alpha}} \zeta_{\hat{\alpha}, \lambda}>0$, and thus, after a decline in $\lambda$ this effect is a source of domestic job losses for offshoring firms.

A decline in the offshoring cost also improves the productivity of firms engaged in offshoring: their marginal costs $\left(\frac{c(\hat{\alpha}) \hat{w}_{Z}}{\varphi}\right)$ decline, as they can purchase inputs abroad at a lower cost: $\zeta_{c(\hat{\alpha}), \lambda}>0$. The lower marginal cost allows these firms to charge lower prices and increase their market shares. We call the impact of the increased productivity on the demand for domestic labor the "productivity effect". In equation (34) the productivity effect is given by $-(\sigma-\rho) \zeta_{c(\hat{\alpha}), \lambda}$. Note that whether the increased demand for the offshoring firm's product translates into greater domestic employment at the firm level depends on two parameters, $\sigma$ and $\rho$. The higher the elasticity of substitution between varieties $(\sigma)$, the greater the increase in the demand for the good of a firm whose marginal cost declines. On the other hand, a high elasticity of substitution between inputs $(\rho)$ - so that domestic labor can be easily replaced by cheaper foreign labor-reduces the likelihood that the increase in demand for the firm's output translates into an increase in demand for domestic labor. In the end, after a decline in $\lambda$, the firm's domestic-labor demand increases through the productivity channel if and only if $\rho<\sigma$. In general, note that the productivity effect on employment is stronger the higher $\sigma$ is and the lower $\rho$ is.

From (26) we know that the firm demand for labor and $\hat{\varphi}$ have an inverse relationship: an increase in $\hat{\varphi}$ reduces the residual demand for each firm, which negatively affects firm-level profitssee equation (21) - and firm-level labor demand. We term the impact on a firm's labor demand resulting from a change in $\hat{\varphi}$ the "competition effect". In equation (34) the competition effect is given by $-(\sigma-1) \zeta_{\hat{\varphi}, \lambda}>0$ and thus, after a decline in $\lambda$ this effect is a source of job losses for all firms. One way to intuitively understand this effect is that an increase in $\hat{\varphi}$ is associated with a decrease in the aggregate price index, $P$ - see equation (20). A decrease in $P$ is akin to a toughening of the competitive environment, leading to a decline in the demand for a firm's product and consequently to a decline in the firm's demand for labor.

Equation (34) misses the labor-demand responses of firms whose offshoring status changes: initially non-offshoring firms that start to offshore, and vice versa. More explicitly, in equation (34) the offshoring cutoff rule, $\hat{\varphi}_{o}$, separates non-offshoring and offshoring firms, but $\hat{\varphi}_{o}$ also changes with $\lambda$. In particular, $\zeta_{\hat{\varphi}_{o}, \lambda}>0$ in Lemma 4 implies that $\hat{\varphi}_{o}$ declines after a decline in $\lambda$. In this case, those firms between the new and old $\hat{\varphi}_{o}$ face a discontinuity in their domestic-labor demands as they begin to offshore: these firms' domestic-labor demands jump from $L_{n}(\varphi)$ to $L_{o}(\varphi)$. From equation (26) note that when a firm changes from $L_{n}(\varphi)$ to $L_{o}(\varphi)$ due to a decline in $\lambda$, the same three effects described above are present and the only source of job creation is the productivity effect if $\rho<\sigma$. 
The following proposition shows the net effects of a change in the variable cost of offshoring on firm-level employment.

\section{Proposition 1. (Offshoring costs and firm-level employment)}

A decline in the offshoring cost, $\lambda$, causes: (i) the death of the least productive non-offshoring firms, who then destroy all their jobs; (ii) job destruction at surviving non-offshoring firms; (iii) an ambiguous domestic labor response at existing offshoring firms if $\rho<\bar{\rho}$, where $\bar{\rho} \in(1, \sigma)$, but job destruction otherwise; (iv) an ambiguous domestic labor response at existing firms that begin to offshore if $\rho<\sigma$, but job destruction otherwise.

Part (i) refers to the job destruction due to the death of firms between the old and new $\hat{\varphi}$ these firms are wiped out due to the competition effect. Part (ii) refers to non-offshoring firms that survive after the decline in offshoring costs. Equation (34) shows that for these firms only the competition effect is present and hence, each of these firms destroys domestic jobs by contraction. Part (iii) refers to firms that offshore before and after the decline in offshoring costs. For these firms the impact of a change in $\lambda$ on domestic employment is given by the second line of (34) and they are subject to all the effects described above: the job-relocation effect, the productivity effect, and the competition effect. The productivity effect dominates the competition effect if and only if $\rho<\bar{\rho}$, where $\bar{\rho} \in(1, \sigma)$. If that is the case, and without further assumptions about the job-relocation effect, the net impact on firm-level employment is ambiguous. Given that $\bar{\rho}>1$, it follows that if there is complementarity between inputs $(\rho<1)$, the productivity effect always dominates the competition effect, making job creation by expansion more likely. ${ }^{13}$ In the case of $\rho \geq \bar{\rho}$, the productivity effect does not dominate the competition effect and hence, $\zeta_{L_{o}(\varphi), \lambda}>0$ and these firms experience job losses. Lastly, part (iv) refers to the labor-demand response of firms that begin to offshore after the decline in offshoring costs. For these firms, the job-relocation and competition effects cause job destruction, while the productivity effect causes job creation if and only if $\rho<\sigma$.

\subsection{Industry-Level Employment Responses}

This section describes how a change in the offshoring cost, $\lambda$, affects the composition of firms and total domestic employment in the differentiated-good sector. The following proposition describes the changes in the mass of active firms, the mass of offshoring firms, and the mass of entrants when $\lambda$ declines.

\footnotetext{
${ }^{13}$ As mentioned in section 1.1, Harrison and McMillan (2011) find empirical evidence showing that offshoring causes job creation in U.S. multinational firms that perform complementary tasks at home and abroad, and job destruction if tasks are substitutes.
} 


\section{Proposition 2. (Offshoring costs and the mass of firms)}

After a decline in $\lambda$, the mass of offshoring firms, $N_{o}$, increases. However, there is an ambiguous response in the mass of entrants, $N_{E}$, the mass of active firms, $N$, and the mass of non-offshoring firms, $N_{n}$. The higher the value of $\eta$, the more likely it is that $N_{E}, N$, and $N_{n}$ increase after a decline in $\lambda$. In the special case with $\eta \rightarrow 1, N_{E}, N$, and $N_{n}$ decline.

In spite of the tougher competitive environment and the exit of some low productivity nonoffshoring firms, which cannot survive the competition from (the now more productive) offshoring firms, the effect on $N_{E}, N$, and $N_{n}$ is ambiguous due to the role played by the elasticity of demand for differentiated goods, $\eta$. If $\eta$ is high, a decline in $\lambda$ causes a large reallocation of expenditure towards differentiated goods, driving entry up. Even with a low $\eta$, the increase in the fraction of offshoring firms is large enough to lead to an increase in $N_{o}$.

Now, we can separate out the extensive- and intensive-margin components of net domestic employment changes in the differentiated-good sector. Taking the derivative of equation (27) with respect to $\lambda$, we find that the effect of $\lambda$ on $L_{z}$ can be decomposed into its extensive- and intensivemargin components as

$$
\begin{aligned}
\frac{d L_{Z}}{d \lambda}= & \underbrace{\left[-L_{n}(\hat{\varphi}) g(\hat{\varphi}) \frac{d \hat{\varphi}}{d \lambda}\right] \frac{N_{E}}{\delta}+\frac{L_{Z}}{N_{E}} \frac{d N_{E}}{d \lambda}}_{\text {Net extensive margin }}+ \\
& \underbrace{\left[\left(L_{n}\left(\hat{\varphi}_{o}\right)-L_{o}\left(\hat{\varphi}_{o}\right)\right) g\left(\hat{\varphi}_{o}\right) \frac{d \hat{\varphi}_{o}}{d \lambda}+\int_{\hat{\varphi}}^{\hat{\varphi}_{o}} \frac{d L_{n}(\varphi)}{d \lambda} g(\varphi) d \varphi+\int_{\hat{\varphi}_{o}}^{\infty} \frac{d L_{o}(\varphi)}{d \lambda} g(\varphi) d \varphi\right] \frac{N_{E}}{\delta}}_{\text {Net intensive margin }} .
\end{aligned}
$$

The net extensive margin consists of two components: the change in domestic employment due to non-offshoring firms that stop (or start) producing because of the effect of $\lambda$ on $\hat{\varphi}$, and the change in domestic employment due to the effect of $\lambda$ on on the mass of entrants, $N_{E}$. The net intensive margin has three components: the first term accounts for the change in domestic employment of firms that change their offshoring status due to the effect of $\lambda$ on $\hat{\varphi}_{o}$; the second term accounts for the change in domestic employment of continuing non-offshoring firms; and the third term accounts for the change in domestic employment of continuing offshoring firms. The following proposition looks at each of the components of equation (35).

\section{Proposition 3. (Offshoring costs and net changes in sector- $Z$ 's employment)}

$A$ decline in $\lambda$ has the following effects on domestic employment in the differentiated-good sector: (i) an ambiguous net effect at the extensive margin: job destruction is more likely when $\eta$ approaches 1 , and job creation is more likely when $\eta$ approaches $\sigma$; (ii) an ambiguous net effect at the intensive margin if $\rho<\sigma$ but job destruction otherwise; (iii) an ambiguous effect overall: net job creation is more likely for higher $\eta$ and lower $\rho$. If $\eta \rightarrow 1$ and $\rho \geq 1$, net job destruction is guaranteed. 
Regarding part (i), the net effect at the extensive margin is ambiguous - in spite of the destruction of domestic jobs due to the death of non-offshoring firms between the old and new $\hat{\varphi}$ - due to the ambiguity of $N_{E}$ discussed in Proposition 2. In the $\eta \rightarrow 1$ case, $N_{E}$ declines and hence there is job destruction at the extensive margin. Part (ii) concerns the signs and relative magnitudes of the three net-intensive-margin components in equation (35). Expanding the results in Proposition 1, we obtain that even though surviving non-offshoring firms destroy domestic jobs after a decline in $\lambda$ (positive sign for the second term), the ambiguous domestic employment response of new and existing offshoring firms - ambiguous signs for the first term (if $\rho<\sigma)$ and third term (if $\rho<\bar{\rho}$ ) carries over to the overall net-intensive-margin effect. Adding the extensive and intensive margins, we obtain that the overall effect of a decline in offshoring costs is ambiguous in general; however, net job creation is more likely the higher the $\eta$ and the lower the $\rho$. In the special case with $\eta \rightarrow 1$ and $\rho \geq 1$, the job destruction at the extensive margin dominates any possible job creation at the intensive margin.

An interesting implication of these results is that the impact of offshoring on jobs differs across industries. In industries where there is a strong complementarity between domestic and offshored inputs (very low $\rho$ ) or the elasticity of demand for the industry's product is high (high $\eta$ ), then offshoring may lead to an increase in employment. In other cases, however, a decrease in employment is the more likely outcome.

\subsection{Offshoring Costs and the Economy-Wide Unemployment Rate}

From (30) we know that the economy-wide unemployment rate is $u=u_{H} \frac{\mathbb{L}_{H}}{\mathbb{L}}+u_{Z} \frac{\mathbb{L}_{Z}}{\mathbb{L}}$. Also, equations (8), (14), and (28) imply that sectoral unemployment rates, $u_{H}$ and $u_{Z}$, depend exclusively on search friction parameters and, therefore, are not affected by offshoring costs. ${ }^{14}$ Thus, a change in offshoring costs affects the economy-wide unemployment rate only through its impact on the workforce composition. Given that $\mathbb{L}_{H}=\mathbb{L}-\mathbb{L}_{Z}$ and using equation (31), we can rewrite (30) as

$$
u=u_{H}+\left(\frac{u_{Z}-u_{H}}{1-u_{Z}}\right) \frac{L_{Z}}{\mathbb{L}} .
$$

It follows that

$$
\frac{d u}{d \lambda}=\left[\frac{u_{Z}-u_{H}}{\mathbb{L}\left(1-u_{Z}\right)}\right] \frac{d L_{Z}}{d \lambda}
$$

and hence $\frac{d u}{d \lambda}$ and $\frac{d L_{Z}}{d \lambda}$ have the same sign if $u_{Z}>u_{H}$, and they have opposite signs if $u_{Z}<u_{H}$.

Suppose the search parameters are such that $u_{Z}<u_{H}$. In this case, if $\eta$ is sufficiently high and $\rho$ is sufficiently low so that a decline in offshoring costs increases the share of the workforce affiliated

\footnotetext{
${ }^{14}$ This result is analogous to the result of independence between final-good trade costs and sectoral unemployment rates in Helpman and Itskhoki (2010).
} 
with sector $Z$, then the economy-wide unemployment rate declines because workers are moving from the high-unemployment sector $(H)$ to the low-unemployment sector $(Z)$. In general, however, we know from Proposition 3 that the impact of offshoring on $L_{Z}$ is ambiguous and therefore, from (37) it follows that the same must be true for the economy-wide unemployment rate. Nevertheless, we can write the following corollary to Proposition 3.

Corollary 1. If search frictions are higher in the differentiated-good sector so that $u_{Z}>u_{H}, a$ decline in offshoring costs is likely to reduce unemployment when $\rho$ is high and $\eta$ is low. If $u_{H}>u_{Z}$, a decline in offshoring costs is likely to reduce unemployment when $\rho$ is low and $\eta$ is high.

\subsection{Numerical Exercise}

This section presents a numerical exercise that highlights the effects of offshoring costs on firmand industry-level domestic employment in the differentiated-good sector, and on the economy-wide unemployment rate. It also shows how these effects depend on both the degree of substitutability/complementarity across inputs, $\rho$, and the elasticity of demand for differentiated goods, $\eta$.

Our labor-market search friction parameters are $\beta=0.5, m_{H}=m_{Z}=1, \gamma_{H}=0.52$, and $\gamma_{Z}=0.58$. These parameters imply $w_{H}=0.5, \theta_{H}=0.92, w_{Z}=0.53, \theta_{Z}=0.83, \hat{w}_{Z}=1.06$, and a higher unemployment rate in the differentiated-good sector: $u_{H}=3.85 \%$ and $u_{Z}=8.96 \%$. The cost of hiring a unit of foreign labor, $w^{*}$, is 0.5 . We assume that the productivity of firms in the differentiated-good sector is Pareto distributed in the interval $\left[\varphi_{\min }, \infty\right)$ with the cumulative distribution function, $G(\varphi)=1-\left(\frac{\varphi_{\min }}{\varphi}\right)^{\psi}$, where $\psi$ is the parameter of productivity dispersion (a higher $\psi$ implies less heterogeneity). ${ }^{15}$ We assume $\varphi_{\min }=1, \psi=3.5$, and set the elasticity of substitution between varieties, $\sigma$, to 3.5. The size of the workforce, $\mathbb{L}$, is set to 15 and the sunk entry cost $f_{E}=0.8$. The fixed cost of operation and the fixed cost of offshoring, $f$ and $f_{o}$, are set to 0.05 . We assume that $12 \%$ of firms receive the exogenous death shock at the end of every period: $\delta=0.12$. For the functional form of $k(\alpha)$, we assume that $k(\alpha)=e+b \alpha^{d}$, where $e, b$, and $d$ are positive constants. It follows that $\hat{\alpha}=\left[\frac{1}{b}\left(\frac{\hat{w}_{Z}}{\lambda w^{*}}-e\right)\right]^{\frac{1}{d}}$. Let us assume that $e=1, b=20$, and $d=2.5$. These values, along with $w^{*}=0.5$ and $\hat{w}_{z}=1.06$, imply that for an interior solution to exist $(\hat{\alpha} \in(0,1))$ and to satisfy $\lambda k(\alpha)>1$ for every $\alpha$, it must be the case that $\lambda \in(1,2.12)$. Besides $\lambda$, we also allow $\rho$ and $\eta$ to vary.

Let us now look at firm-level employment responses in the differentiated-good sector when $\lambda$ changes. Let $L(\varphi)$ denote the demand for domestic labor of a firm with productivity $\varphi$ so that $L(\varphi)=0$ if $\varphi<\hat{\varphi}, L(\varphi)=L_{n}(\varphi)$ if $\varphi \in\left[\hat{\varphi}, \hat{\varphi}_{o}\right)$, and $L(\varphi)=L_{o}(\varphi)$ if $\varphi \geq \hat{\varphi}_{o}$, where $L_{s}(\varphi)$ is

\footnotetext{
${ }^{15}$ The theoretical results established earlier do not hinge on the assumption of a particular distribution. We use the Pareto distribution for this numerical exercise because of its wide popularity in international trade models with heterogeneous firms, but similar results are obtained with other commonly used distributions.
} 


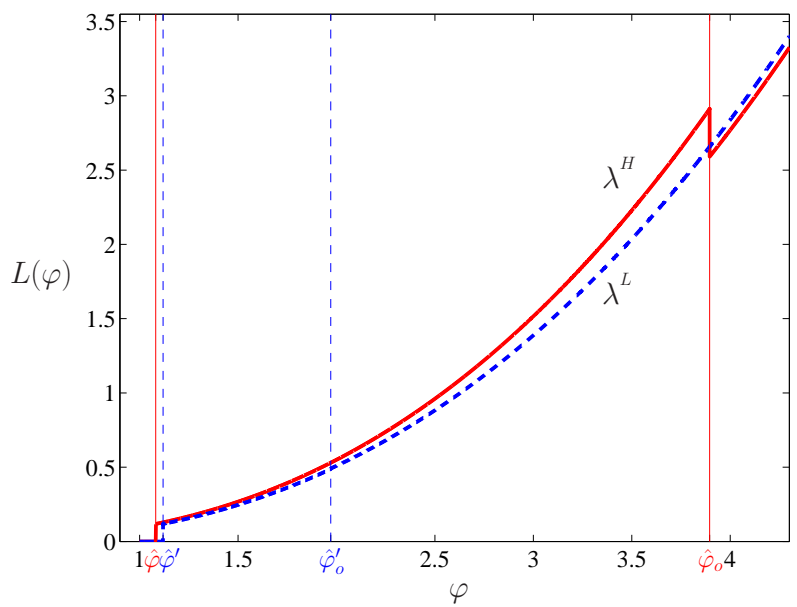

(a) Perfect input complementarity $(\rho=0)$

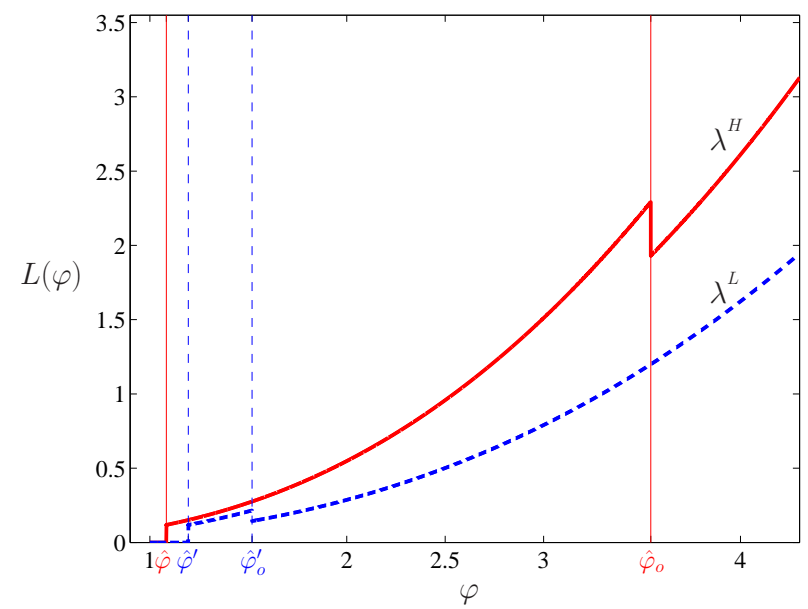

(b) High input substitutability $(\rho=4>\sigma)$

Figure 1: Firm-level demand for domestic labor in differentiated-good sector: High offshoring cost $\left(\lambda^{H}=1.8\right)$ and low offshoring cost $\left(\lambda^{L}=1.2\right)$

defined as in Lemma 3, for $s \in\{n, o\}$. Importantly, the elasticity of demand for $Z$, $\eta$, does not affect firm-level labor outcomes because $\hat{\alpha}, \hat{w}_{z}, \hat{\varphi}$, and $\hat{\varphi}_{o}$ are independent of $\eta$, and therefore, $L(\varphi)$ is also independent of $\eta$.

Figure 1 shows $L(\varphi)$ for a high offshoring cost $\left(\lambda^{H}=1.8\right)$ and a low offshoring $\operatorname{cost}\left(\lambda^{L}=1.2\right)$ under two cases: perfect input complementarity $(\rho=0)$ and high input substitutability $(\rho=4$, with $\rho>\sigma)$. In both cases, the decline in $\lambda$ causes an increase in the cutoff level that determines whether or not a firm produces (from $\hat{\varphi}$ to $\hat{\varphi}^{\prime}$ ), and a decline in the cutoff level that separates offshoring and non-offshoring firms (from $\hat{\varphi}_{o}$ to $\hat{\varphi}_{o}^{\prime}$ ). Thus, each figure shows five types of firms after a decline in $\lambda$ : firms that never produce $(\varphi<\hat{\varphi})$, non-offshoring firms that stop producing $\left(\hat{\varphi} \leq \varphi<\hat{\varphi}^{\prime}\right)$, non-offshoring firms that continue to produce $\left(\hat{\varphi}^{\prime} \leq \varphi<\hat{\varphi}_{o}^{\prime}\right)$, firms that begin to offshore $\left(\hat{\varphi}_{o}^{\prime} \leq \varphi<\hat{\varphi}_{o}\right)$, and continuing offshoring firms $\left(\varphi \geq \hat{\varphi}_{o}\right)$. From both figures, note that after a decline in $\lambda$, we only observe job creation (though very small) for continuing offshoring firms in the case of perfect input complementarity — for these firms, the productivity effect dominates both the competition and job-relocation effects. For all other firms with $\varphi \geq \hat{\varphi}$, the decline in $\lambda$ causes job destruction: by death for firms with productivities between $\hat{\varphi}$ and $\hat{\varphi}^{\prime}$, and by contraction for the rest of the firms.

The comparison of Figures $1 \mathrm{a}$ and $1 \mathrm{~b}$ highlights one of the main results of this paper: the crucial role of input complementarity/substitutability in determining the impact of offshoring on domestic employment. Note that the negative impact of a decline in $\lambda$ on firm-level employment is much larger for the case of high input substitutability. To look further at this issue, Figure 2 shows - from equation (27) - the relationship between $\lambda$ and total domestic employment in the 


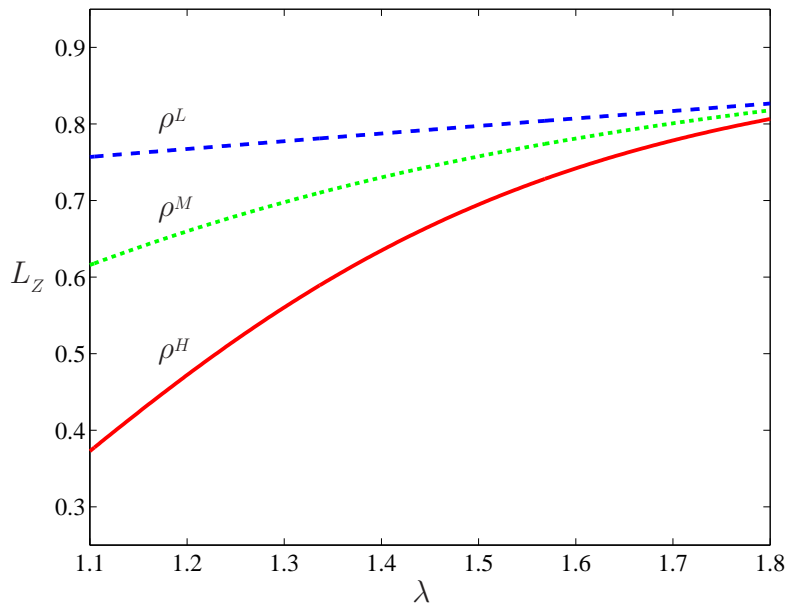

(a) Low elasticity of demand for $Z(\eta=1.5)$

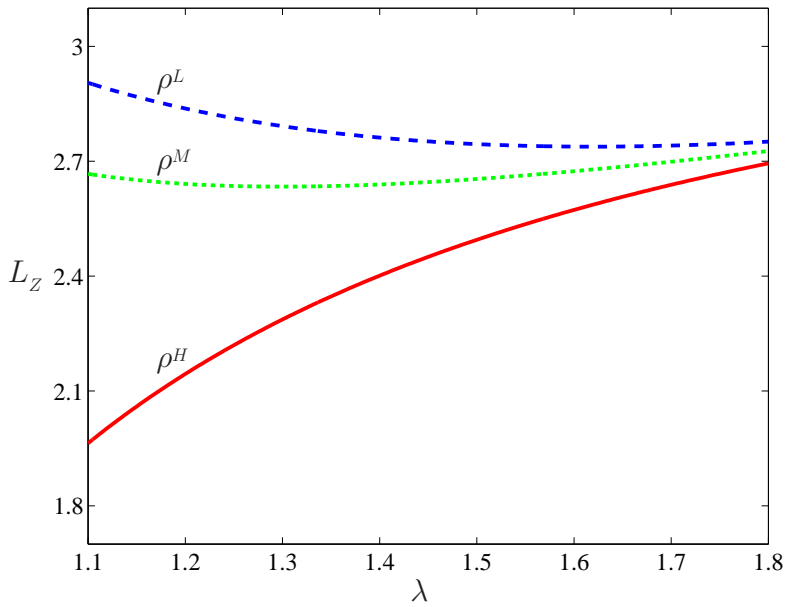

(b) High elasticity of demand for $Z(\eta=2.5)$

Figure 2: Total domestic employment in differentiated-good industry: Perfect input complementarity $\left(\rho^{L}=0\right)$, moderate input substitutability $\left(1<\rho^{M}=2<\sigma\right)$, high input substitutability $\left(\rho^{H}=4>\sigma\right)$

differentiated-good industry, $L_{Z}$, for three levels of $\rho$-perfect input complementarity $\left(\rho^{L}=0\right)$, moderate input substitutability $\left(\rho^{M}=2\right.$, with $\left.\rho^{M}<\sigma\right)$, and high input substitutability $\left(\rho^{H}=4\right.$, with $\rho^{H}>\sigma$ ) -and two levels of $\eta, 1.5$ and 2.5. At the industry level, a higher value of $\rho$ is associated with more job destruction.

Figure 2 also highlights the role played by the elasticity of demand for differentiated goods, $\eta$. Although $\eta$ does not affect firm-level outcomes, it affects industry-level employment by altering how the expenditure of households is allocated between homogeneous and differentiated goods: with a high $\eta$, a decline in $\lambda$ causes a large reallocation of expenditure towards differentiated goods, which drives entry up, and may cause net job creation in the $Z$ sector. This is clearly seen in Figure $2 \mathrm{~b}$ when there is perfect input complementarity $\left(\rho^{L}=0\right)$, and for very low levels of $\lambda$ when there is moderate input substitutability $\left(\rho^{M}=2\right)$. Hence, a decline in $\lambda$ is more likely to cause net job creation in the differentiated-good sector the higher the $\eta$ and the lower the $\rho$.

The economy-wide unemployment rate follows the same behavior as $L_{z}$ in Figure 2. This is the case because in this numerical example $u_{Z}>u_{H}$ and thus, $u$ declines if $L_{Z}$ decreases because workers searching for jobs shift from the high-unemployment sector $(Z)$ to the low-unemployment sector $(H)$. Similarly, $u$ increases in response to a decrease in $\lambda$ in Figure $2 \mathrm{~b}$ when $\eta$ is high and $\rho$ is low because more workers are now searching for jobs in the high-unemployment sector, $Z$. If we had assumed instead search parameters so that $u_{Z}<u_{H}$, then $u$ and $L_{Z}$ would move in opposite directions. 


\subsection{Offshoring and Welfare}

While the focus of our paper is on the employment effects of offshoring, we can also derive welfare implications. Note from equation (3) that the welfare of the representative household is inversely related to the price index, $P$, and positively related to the spending, E. From (6) and (33), it follows that $E$ does not change in response to a change in $\lambda$ or $f_{o}$. Since $P$ declines in response to either a decline in $\lambda$ or $f_{o}$ ( $\hat{\varphi}$ increases when $\lambda$ or $f_{o}$ decline, and from (20) we know that $P$ and $\hat{\varphi}$ have an inverse relationship) we obtain the following result.

\section{Proposition 4. (Offshoring and Welfare)}

A decrease in the cost of offshoring (fixed or variable) leads to an increase in welfare.

Intuitively, offshoring always leads to productivity improvements for the economy, which shows up in a lower price index for differentiated goods and consequently in an increase in welfare. The result above is notable because we have labor market frictions in the model and it is possible for a decrease in the cost of offshoring to lead to an increase in unemployment. As well, our assumption of a representative household implies everyone gains from offshoring. As mentioned in the Introduction, some caveats about this result are in order. First, in reality labor income risk cannot be diversified away, which means that unemployed workers have lower welfare than employed workers; an increase in unemployment induced by offshoring creates some losers-the newly unemployed. Second, if workers are highly risk averse, any increase in unemployment caused by offshoring can inflict large losses on workers by increasing the labor market risk, which then must be weighed against the efficiency gains inherent in the proposition above. Since the focus of this paper is on identifying the channels through which offshoring affects unemployment, we abstract from these broader welfare issues by relying on the simplifying assumption of a risk neutral representative household.

\section{Search Frictions and Jobs}

The impact of a change in search frictions can be easily studied in our model. The key equation for this analysis is equation (15), which we recall is $\hat{w}_{Z} \equiv \frac{m_{H}}{m_{Z}}\left(\frac{\gamma_{Z}}{\gamma_{H}}\right)^{1-\beta}$. That is, search friction parameters affect jobs by altering the cost of hiring a unit of domestic labor in the differentiatedgood sector, $\hat{w}_{z}$. Given that $\beta \in(0,1)$, note that $\hat{w}_{z}$ is increasing in $\gamma_{z}$ and $m_{H}$, and decreasing in $\gamma_{H}$ and $m_{Z}$. There is a reduction in search frictions in sector $i$ when either $\gamma_{i}$ declines or $m_{i}$ increases. Therefore, a reduction in search frictions in the differentiated-good sector lowers $\hat{w}_{Z}$, and a reduction in search frictions in the homogeneous-good sector increases $\hat{w}_{z}$. The following 
lemma contains results that will allow us to understand the effects of changes in search frictions on offshoring decisions and jobs.

Lemma 5. $\zeta_{\hat{\alpha}, \hat{w}_{Z}}>0, \zeta_{c(\hat{\alpha}), \hat{w}_{Z}}<0, \zeta_{\hat{\varphi}_{,} \hat{w}_{Z}}>0, \zeta_{\hat{\varphi}_{o}, \hat{w}_{Z}}<0$.

By lowering $\hat{w}_{z}$, a decrease in search frictions in the differentiated-good sector makes offshoring less attractive, which in turn reduces the fraction of offshored inputs, $\zeta_{\hat{\alpha}, \hat{w}_{Z}}>0$, and erodes the relative cost advantage of offshoring firms, $\zeta_{c(\hat{\alpha}), \hat{w}_{Z}}<0$. The proportional decrease in the marginal cost of offshoring firms is less than that of non-offshoring firms, which leads to a softening of the competitive environment: $\zeta_{\hat{\varphi}, \hat{w}_{z}}>0$. As well, the reduced attractiveness of offshoring leads to an increase in the offshoring productivity cutoff: $\zeta_{\hat{\varphi}_{o}, \hat{w}_{Z}}<0$.

From (26) we obtain that the elasticity of firm-level domestic employment, $L_{s}(\varphi)$, with respect to $\hat{w}_{Z}$ is given by

$$
\zeta_{L_{s}(\varphi), \hat{w}_{Z}}= \begin{cases}-(\sigma-1) \zeta_{\hat{\varphi}, \hat{w}_{Z}}-1 & \text { if } s=n \\ -\frac{\hat{\alpha}}{1-\hat{\alpha}} \zeta_{\hat{\alpha}, \hat{w}_{Z}}-(\sigma-\rho) \zeta_{c(\hat{\alpha}), \hat{w}_{Z}}-(\sigma-1) \zeta_{\hat{\varphi}^{,} \hat{w}_{Z}}-1 & \text { if } s=o .\end{cases}
$$

After a decline in $\hat{w}_{z}$, employment at non-offshoring firms increases not only because of the competition effect, $-(\sigma-1) \zeta_{\hat{\varphi}, \hat{w}_{Z}}<0$, but also because of the direct effect of a decrease in their marginal cost and the consequent increase in demand (accounted for by -1 ). For offshoring firms we again have the three effects - job relocation, competition, and productivity - in addition to the direct effect of a lower marginal cost. As before, the productivity effect moves in the opposite direction to the other effects if $\rho<\sigma$, and in the same direction otherwise. Also $\hat{\varphi}_{o}$ increases, so there are firms that stop offshoring - for these firms we observe the four effects directly from (26).

\section{Proposition 5. (Search frictions and differentiated-good-sector employment)}

$A$ decline in search frictions in sector $Z$-or an increase in search frictions in sector $H-$ lowers $\hat{w}_{Z}$, which affects sector-Z's domestic employment and the mass of firms as follows: (i) job creation due to the birth of low productivity non-offshoring firms; (ii) job creation at continuing non-offshoring firms; (iii) an ambiguous domestic labor response at continuing offshoring firms if $\rho<\tilde{\rho}$, where $\tilde{\rho}<\sigma-1$, but job creation otherwise; (iv) an ambiguous response at firms that switch from offshoring to non-offshoring if $\rho<\sigma$, but job creation otherwise; (v) increases in $N_{E}, N$, and $N_{n}$, but an ambiguous response in $N_{o}$; (vi) net job creation at the extensive margin, and an ambiguous response at the intensive margin and overall if $\rho<\sigma$, but net job creation otherwise. Finally, higher $\eta$ and $\rho$ promote stronger job creation when $\hat{w}_{z}$ declines.

One key difference from the case of a change in offshoring costs is that a change in search frictions affects the economy-wide unemployment rate not only through its impact on the workforce 


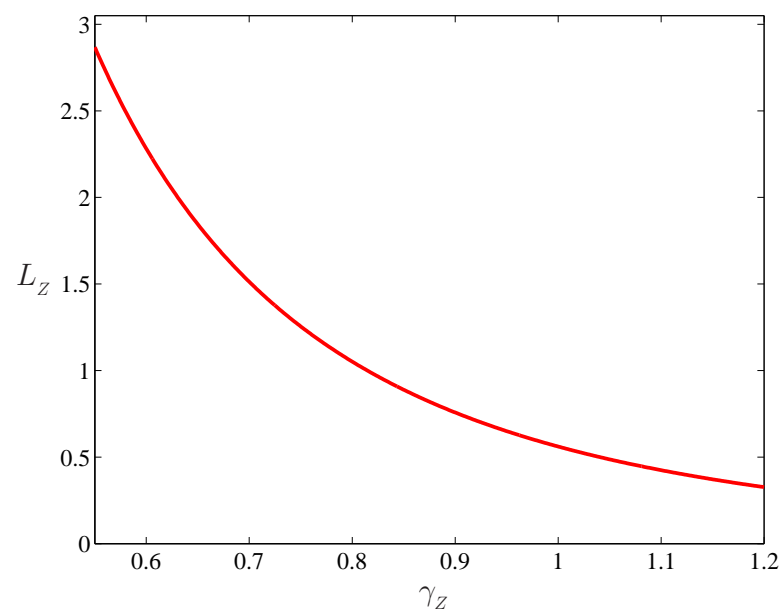

(a) Differentiated-good-sector domestic employment

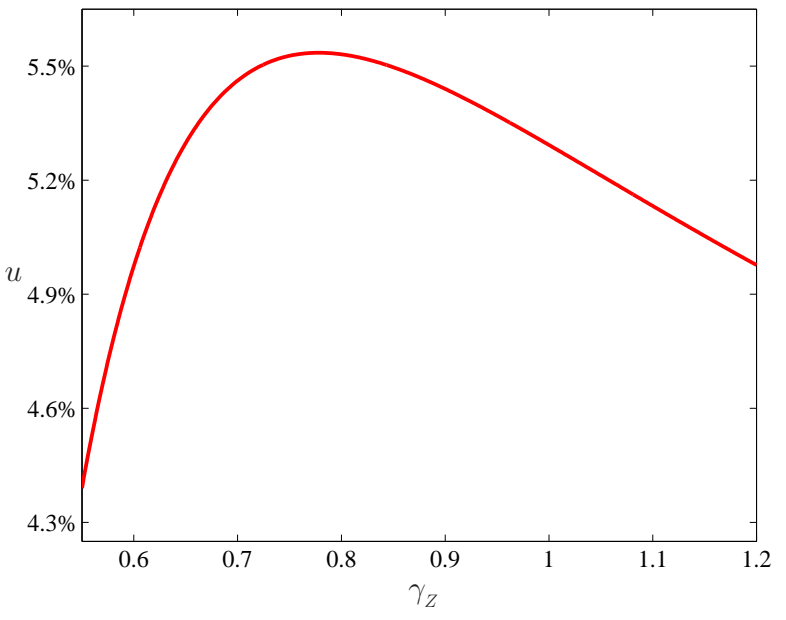

(b) Economy-wide unemployment rate

Figure 3: Search frictions in differentiated-good sector and unemployment

composition, but also through its effect on sectoral unemployment rates. For example, a decline in $\gamma_{Z}$ affects $L_{Z}$ via a decrease in $\hat{w}_{z}$, but also causes a decline in $u_{z}$-see (14) and (28). From (36) note that, as opposed to the simpler response for a change in $\lambda$ in (37), the response of $u$ to a change in $\gamma_{Z}$ is given by

$$
\frac{d u}{d \gamma_{Z}}=\frac{1}{\left(1-u_{Z}\right) \mathbb{L}}\left[\left(u_{Z}-u_{H}\right) \frac{d L_{Z}}{d \hat{w}_{Z}} \frac{d \hat{w}_{Z}}{d \gamma_{Z}}+\left(\frac{1-u_{H}}{1-u_{Z}}\right) \frac{d u_{Z}}{d \gamma_{Z}} L_{Z}\right] .
$$

An interesting possibility is the following perverse result. Even though $u_{z}$ is smaller after a decline in $\gamma_{Z}$, an increase in the number of workers searching for a job in that sector may raise the economy-wide unemployment rate if $u_{Z}$ was higher than $u_{H}$ to begin with. This possibility is verified numerically in Figure 3. We assume the same parameter values as in section 3.4, along with $\lambda=1.5, \rho=4$, and $\eta=2.5$. Note that the relationship between $\gamma_{Z}$ and $u$ has an inverted-U shape: there is a region where the reallocation of job search towards the high-unemployment sector $(Z)$ causes an increase in $u$ despite the decline in $u_{Z}$ induced by a decrease in $\gamma_{Z}{ }^{16}$

\section{The Model with Trade in Differentiated Goods}

To highlight the effects of offshoring costs on domestic jobs due to input trade, the previous model abstracts from trade in differentiated goods. However, it is possible that better offshoring opportunities - as reflected in lower offshoring costs - also expand differentiated-good trade: when

\footnotetext{
${ }^{16}$ From Proposition 5 we know that the effects of an increase in sector- $H$ 's search frictions on differentiatedgood-sector employment are similar to those of a decline in sector- $Z$ 's frictions. However, the implications for the economy-wide unemployment rate could be quite different. Consider, for example, a change in $\gamma_{H}$. Note from (8) and (14) that $\gamma_{H}$ affects labor market tightness in both sectors, $\theta_{H}$ and $\theta_{Z}$, and therefore, it affects both sectoral unemployment rates, $u_{H}$ and $u_{Z}$. Hence, a change in $\gamma_{H}$ affects $u$ in (36) through its impact on $u_{H}, u_{Z}$, and $L_{Z}$.
} 
a firm begins to offshore, it becomes more competitive in both domestic and foreign final-good markets. Hence, offshoring costs affect jobs through their impact on trade in differentiated goods as well. To analyze these employment effects, this section introduces an explicit North-South version of the model with trade in both intermediate inputs and final goods.

There are two countries, North and South, and two production sectors in each country: a homogenous-good sector and a differentiated-good sector. The homogeneous good is traded costlessly and is produced under perfect competition, while each variety of the differentiated good is potentially tradable and is produced under monopolistic competition. Each country is inhabited by a continuum of households in the unit interval. The number of workers in each household is $\mathbb{L}$ in the North, and $\mathbb{L}^{*}$ in the South. We denote the variables for the South with a star $\left(^{*}\right)$.

The description of preferences, demand, and the labor market for the North is similar to sections 2.1 and 2.2. Since our focus is on the North labor market, we abstract from any labor imperfections in the South and assume it has a perfectly competitive labor market. One unit of Southern labor produces $w^{*}<1$ units of the homogeneous good, and therefore, the wage in the South is $w^{*}$ as long as some homogeneous good is produced there - which we assume to be the case. The preferences of the representative household in the South are the same as in the North and hence, the South's market demand for variety $\omega$ is $z^{* c}(\omega)=p^{*}(\omega)^{-\sigma} P^{* \sigma-\eta}$, where $p^{*}(\omega)$ is the Southern price of variety $\omega$ and $P^{*}$ is the South's differentiated-good price index. The aggregate spending in the South is simply $E^{*}=w^{*} \mathbb{L}^{*}$.

In both countries, producers in the differentiated-good sector are heterogeneous in productivity. After drawing its productivity, each firm decides whether or not to produce for the domestic and export markets. The decision to produce or not for a market is determined by the ability of the firm to cover the fixed cost of selling in that market. Thus, in this extension there is two-way trade in final differentiated goods. Moreover, costless trade in the homogeneous good ensures trade balance between the two countries. As before, we assume that $w^{*}<\hat{w}_{Z}$, so that the differentiated-good producing firms in the North have an incentive to offshore input production to the South.

To keep the analysis tractable in the North-South extension, we make the simplifying assumption that there are no fixed costs of offshoring $\left(f_{o}=0\right)$, so that every producing firm in the North offshores. This allows us to clearly isolate the channels through which variable offshoring costs affect job flows and the economy-wide unemployment rate via their impact on trade in final goods. ${ }^{17}$

The production function of a Northern firm with productivity $\varphi$ is defined as in section 2.3.1.

\footnotetext{
${ }^{17}$ In section B.4 in the Appendix we show the benchmark case with $f_{o}=0$. In this case, a decrease in $\lambda$ benefits all firms proportionately, and therefore, leaves $\hat{\varphi}$ - the minimum productivity level needed to cover the domestic-market fixed costs - unaffected. However, the intensive-margin effects and the overall effect remain qualitatively similar. Figures B. 1 and B.2 in the Appendix are plotted using the same parameters as in Figures 1 and 2 , except that $f_{o}=0$.
} 
The absence of fixed costs of offshoring implies that every active Northern firm offshores and hence $\hat{\alpha}(\varphi)=\hat{\alpha}$ for each of them. Equation (16) and Lemma 1 hold, and therefore, the marginal cost of a Northern firm with productivity $\varphi$ for selling in the Northern market is $\frac{c(\hat{\alpha}) \hat{w}_{Z}}{\varphi}$. If the Northern firm decides to export its finished good, its marginal cost for selling in the Southern market is $\frac{\tau c(\hat{\alpha}) \hat{w}_{Z}}{\varphi}$, where $\tau>1$ accounts for an iceberg export cost - the Northern firm must ship $\tau$ units of the good for one unit to reach the Southern market. Assuming market segmentation and given CES preferences, the prices that a Northern firm with productivity $\varphi$ sets in the domestic $(D)$ and export $(X)$ markets are given by $p_{D}(\varphi)=\left(\frac{\sigma}{\sigma-1}\right) \frac{c(\hat{\alpha}) \hat{w}_{Z}}{\varphi}$ and $p_{X}(\varphi)=\left(\frac{\sigma}{\sigma-1}\right) \frac{\tau c(\hat{\alpha}) \hat{w}_{Z}}{\varphi}$, respectively. Using these pricing equations and the market demand functions, we obtain that this firm's gross profit functions - before deducting fixed costs - from selling in the domestic and export markets are $\pi_{D}(\varphi)=\frac{1}{\sigma} p_{D}(\varphi)^{1-\sigma} P^{\sigma-\eta}$ and $\pi_{X}(\varphi)=\frac{1}{\sigma} p_{X}(\varphi)^{1-\sigma} P^{* \sigma-\eta}$, respectively.

Southern firms only use South labor. The production function for a Southern firm with productivity $\varphi$ is $z^{*}(\varphi)=A^{*} \varphi Y^{*}$, where $A^{*}<1$ is an aggregate productivity factor for Southern firms - they are less efficient than Northern firms in the production of differentiated goods - and $Y^{*}=\left(\int_{0}^{1} y^{*}(\alpha)^{\frac{\rho-1}{\rho}} d \alpha\right)^{\frac{\rho}{\rho-1}}$. With $y^{*}(\alpha)=\ell^{*}$, and as $L^{*}=\ell^{*}$, the production function is equivalent to $z^{*}(\varphi)=A^{*} \varphi L^{*}$. The marginal cost for this firm is then $\frac{w^{*}}{A^{*} \varphi}$ from selling domestically, and $\frac{\tau w^{*}}{A^{*} \varphi}$ from selling in the Northern market. Therefore, the prices set by a Southern firm with productivity $\varphi$ are $p_{D}^{*}(\varphi)=\left(\frac{\sigma}{\sigma-1}\right) \frac{w^{*}}{A^{*} \varphi}$ in the domestic market, and $p_{X}^{*}(\varphi)=\left(\frac{\sigma}{\sigma-1}\right) \frac{\tau w^{*}}{A^{*} \varphi}$ in the export market. This firm's gross profit functions from selling in the domestic and export markets are $\pi_{D}^{*}(\varphi)=\frac{1}{\sigma} p_{D}^{*}(\varphi)^{1-\sigma} P^{* \sigma-\eta}$ and $\pi_{X}^{*}(\varphi)=\frac{1}{\sigma} p_{X}^{*}(\varphi)^{1-\sigma} P^{\sigma-\eta}$, respectively.

\subsection{Equilibrium in the North-South Model}

There are fixed costs of selling in each market. These fixed costs along with the CES demand system imply the existence of cutoff productivity levels that determine the tradability of each differentiated good in each market. For Northern firms there are two cutoff productivity levels: one for selling in the domestic market, $\hat{\varphi}_{D}$, and one for selling in the South, $\hat{\varphi}_{X} \cdot{ }^{18}$ Similarly, $\hat{\varphi}_{D}^{*}$ and $\hat{\varphi}_{X}^{*}$ denote the cutoff productivity levels for Southern firms.

As before, we assume that all fixed costs are in terms of the homogeneous good. For $r \in\{D, X\}$, let $f_{r}$ be the fixed cost of selling in market $r$ for the Northern firms, and let $f_{r}^{*}$ be the fixed cost of selling in market $r$ for the Southern firms. Therefore, the cutoff productivity levels satisfy $\pi_{r}\left(\hat{\varphi}_{r}\right)=f_{r}$ and $\pi_{r}^{*}\left(\hat{\varphi}_{r}^{*}\right)=f_{r}^{*}$, for $r \in\{D, X\}$. Thus, using the gross profit functions from the

\footnotetext{
${ }^{18}$ This version of the model assumes $f_{o}=0$ so that every producing Northern firm offshores. As in the benchmark model, relaxing this assumption (i.e assuming instead $f_{o}>0$ ) implies the existence of a cutoff productivity level, $\hat{\varphi}_{o}$, above which firms would offshore. Thus, Northern firms would be subject to three cutoff productivity levels: $\hat{\varphi}_{D}$, $\hat{\varphi}_{X}$, and $\hat{\varphi}_{o}$. Depending on the differences between the fixed costs of production, offshoring, and exporting, we can have various possible rankings of these cutoffs.
} 
previous section, we obtain the following zero-cutoff-profit conditions:

$$
\begin{aligned}
& p_{D}\left(\hat{\varphi}_{D}\right)^{1-\sigma} P^{\sigma-\eta}=\sigma f_{D}, \\
& p_{X}\left(\hat{\varphi}_{X}\right)^{1-\sigma} P^{* \sigma-\eta}=\sigma f_{X}, \\
& p_{D}^{*}\left(\hat{\varphi}_{D}^{*}\right)^{1-\sigma} P^{* \sigma-\eta}=\sigma f_{D}^{*}, \\
& p_{X}^{*}\left(\hat{\varphi}_{X}^{*}\right)^{1-\sigma} P^{\sigma-\eta}=\sigma f_{X}^{*} .
\end{aligned}
$$

Combining (40) and (43), and (41) and (42) - and using the pricing equations from the previous section-we obtain

$$
\begin{aligned}
& \hat{\varphi}_{X}^{*}=\left(\frac{f_{X}^{*}}{f_{D}}\right)^{\frac{1}{\sigma-1}}\left[\frac{\tau w^{*}}{A^{*} c(\hat{\alpha}) \hat{w}_{Z}}\right] \hat{\varphi}_{D}, \\
& \hat{\varphi}_{X}=\left(\frac{f_{X}}{f_{D}^{*}}\right)^{\frac{1}{\sigma-1}}\left[\frac{\tau A^{*} c(\hat{\alpha}) \hat{w}_{Z}}{w^{*}}\right] \hat{\varphi}_{D}^{*} .
\end{aligned}
$$

These equations indicate the link between the cutoff levels for firms selling in the same market. Moreover, using the zero-cutoff-profit conditions (40)-(43), we can substitute out $P$ and $P^{*}$ in the gross profit functions from the previous section to rewrite them as

$$
\begin{aligned}
& \pi_{r}(\varphi)=\left(\frac{\varphi}{\hat{\varphi}_{r}}\right)^{\sigma-1} f_{r} \\
& \pi_{r}^{*}(\varphi)=\left(\frac{\varphi}{\hat{\varphi}_{r}^{*}}\right)^{\sigma-1} f_{r}^{*},
\end{aligned}
$$

for $r \in\{D, X\}$.

There is free entry of firms in both countries. Each entrant in either country must pay a sunk entry cost in terms of the homogeneous good. The entry cost in the North is $f_{E}$ and the entry cost in the South is $f_{E}^{*}$. As a firm knows its productivity only after entry, the per-period pre-entry expected profits for Northern and Southern potential entrants are, respectively, given by

$$
\begin{aligned}
& \Pi \equiv \int_{\hat{\varphi}_{D}}^{\infty}\left[\pi_{D}(\varphi)-f_{D}\right] g(\varphi) d \varphi+\int_{\hat{\varphi}_{X}}^{\infty}\left[\pi_{X}(\varphi)-f_{X}\right] g(\varphi) d \varphi, \\
& \Pi^{*} \equiv \int_{\hat{\varphi}_{D}^{*}}^{\infty}\left[\pi_{D}^{*}(\varphi)-f_{D}^{*}\right] g(\varphi) d \varphi+\int_{\hat{\varphi}_{X}^{*}}^{\infty}\left[\pi_{X}^{*}(\varphi)-f_{X}^{*}\right] g(\varphi) d \varphi,
\end{aligned}
$$

where the first term in $\Pi$ and $\Pi^{*}$ represents the expected profits from selling domestically, and the second term represents the expected profits from exporting. Given the exogenous death rate, $\delta$, the value of entry in the North is $\frac{\Pi}{\delta}$ and the value of entry in the South is $\frac{\Pi^{*}}{\delta}$. Therefore, the free-entry conditions are

$$
\begin{aligned}
& \frac{\Pi}{\delta}=f_{E}, \\
& \frac{\Pi^{*}}{\delta}=f_{E}^{*} .
\end{aligned}
$$


We can now define the equilibrium in the North-South model.

Definition 2. Given $\pi_{r}(\varphi), \pi_{r}^{*}(\varphi)$, $\Pi$, and $\Pi^{*}$ in (46), (47), (48) and (49), an equilibrium is a 6-tuple $\left(\hat{w}_{Z}, \hat{\alpha}, \hat{\varphi}_{D}, \hat{\varphi}_{X}, \hat{\varphi}_{D}^{*}, \hat{\varphi}_{X}^{*}\right)$ that solves (15), (16), (44), (45), (50), and (51). A sufficient condition for the existence and uniqueness of equilibrium is that $\tau$ is sufficiently large so that $\hat{\varphi}_{D}<\hat{\varphi}_{X}$ and $\hat{\varphi}_{D}^{*}<\hat{\varphi}_{X}^{*}$.

As is usual in Melitz-type heterogeneous-firm models, we assume that the iceberg export cost is large enough so that $\hat{\varphi}_{D}<\hat{\varphi}_{X}$ and $\hat{\varphi}_{D}^{*}<\hat{\varphi}_{X}^{*}$ : exporting firms always produce for the domestic market. In section C.1 in the Appendix we show the existence and uniqueness of equilibrium under this assumption.

Once we solve for the equilibrium, $P$ and $P^{*}$ are easily determined from (40) and (41). We can also solve for the number of firms selling in each market. Let $N$ and $N^{*}$ denote, respectively, the masses of sellers of differentiated goods in the North and South. In the North, $N$ is composed of a mass of $N_{D}$ Northern firms and a mass of $N_{X}^{*}$ Southern firms, so that $N=N_{D}+N_{X}^{*}$. Similarly, $N^{*}=N_{D}^{*}+N_{X}$, where $N_{D}^{*}$ is the mass of Southern producers selling domestically, and $N_{X}$ is the mass of Northern exporters. In steady state, the firms that die due to the exogenous death shock are exactly replaced by successful entrants so that $\delta N_{r}=\left[1-G\left(\hat{\varphi}_{r}\right)\right] N_{E}$ and $\delta N_{r}^{*}=\left[1-G\left(\hat{\varphi}_{r}^{*}\right)\right] N_{E}^{*}$, where $N_{E}$ and $N_{E}^{*}$ denote the masses of Northern and Southern entrants every period, $G(\varphi)$ is the cumulative distribution function from which Northern and Southern firms draw their productivities after entry, and $r \in\{D, X\}$. Thus, to obtain expressions for $N_{D}, N_{X}, N_{D}^{*}$, and $N_{X}^{*}$ in terms of $\hat{w}_{Z}, \hat{\alpha}$, and the cutoff levels, we need to derive first the expressions for $N_{E}$ and $N_{E}^{*}$. Section C.2 in the Appendix derives $N_{E}$ and $N_{E}^{*}$.

\subsection{Employment}

Employment in the differentiated-good sector in the North is determined as follows. Recall that with $f_{o}=0$, every producing Northern firm offshores. Hence, Northern firms demand Southern labor for inputs in the range $[0, \hat{\alpha}]$, and demand Northern labor for inputs in the range $[\hat{\alpha}, 1]$. Let $L_{r}(\varphi)$ denote the demand for domestic labor of a Northern firm with productivity $\varphi$ to produce for market $r$, where $r \in\{D, X\}$. The following lemma presents $L_{r}(\varphi)$.

Lemma 6. The amount of Northern labor required by a Northern firm with productivity $\varphi$ to produce for market $r$ is given by

$$
L_{r}(\varphi)=\frac{(1-\hat{\alpha})(\sigma-1)}{c(\hat{\alpha})^{1-\rho} \hat{w}_{z}}\left(\frac{\varphi}{\hat{\varphi}_{r}}\right)^{\sigma-1} f_{r} \quad \text { if } \quad \varphi \geq \hat{\varphi}_{r}
$$

and zero otherwise, for $r \in\{D, X\}$. 
Therefore, the total demand for domestic labor of a Northern firm with productivity $\varphi$ is given by

$$
L(\varphi)=L_{D}(\varphi) \cdot \mathbb{I}\left\{\varphi \geq \hat{\varphi}_{D}\right\}+L_{X}(\varphi) \cdot \mathbb{I}\left\{\varphi \geq \hat{\varphi}_{X}\right\}
$$

where $\mathbb{I}\left\{\varphi \geq \hat{\varphi}_{r}\right\}$ is an indicator function taking the value of 1 if $\varphi \geq \hat{\varphi}_{r}$. Given that $\hat{\varphi}_{D}<\hat{\varphi}_{X}$, a Northern firm with productivity $\varphi$ demands no labor if $\varphi<\hat{\varphi}_{D}$, demands labor to produce only for the domestic market if $\varphi \in\left[\hat{\varphi}_{D}, \hat{\varphi}_{X}\right)$, and demands labor to produce for the domestic and export markets if $\varphi \geq \hat{\varphi}_{X}$.

The expression for employment in the differentiated-good sector is obtained as follows. Let $\bar{L}_{r}=\int_{\hat{\varphi}_{r}}^{\infty} L_{r}(\varphi) g\left(\varphi \mid \varphi \geq \hat{\varphi}_{r}\right) d \varphi$ denote the average amount of Northern labor employed by Northern firms to produce for market $r$, for $r \in\{D, X\}$. Hence, the total employment level in the North in the differentiated-good sector is given by $L_{z}=N_{D} \bar{L}_{D}+N_{X} \bar{L}_{X}$, where $N_{r} \bar{L}_{r}$ is the Northern employment devoted to the production of differentiated goods for market $r$. Given that $g(\varphi \mid \varphi \geq$ $\left.\hat{\varphi}_{r}\right)=\frac{g(\varphi)}{1-G\left(\hat{\varphi}_{r}\right)}$ and $N_{r}=\left[1-G\left(\hat{\varphi}_{r}\right)\right] \frac{N_{E}}{\delta}$, we can rewrite $L_{z}$ as

$$
L_{Z}=\frac{N_{E}}{\delta}\left[\int_{\hat{\varphi}_{D}}^{\infty} L_{D}(\varphi) g(\varphi) d \varphi+\int_{\hat{\varphi}_{X}}^{\infty} L_{X}(\varphi) g(\varphi) d \varphi\right] .
$$

Equations (52) and (54) are the key expressions for our analysis of employment in sector $Z$.

Once we know $L_{z}$ we obtain the workforce composition, $\mathbb{L}_{Z}$ and $\mathbb{L}_{H}$, the economy-wide unemployment rate, $u$, the homogeneous-good-sector employment, $L_{H}$, and the aggregate labor income, $E$, in a manner identical to the benchmark case - that is, equations (28)-(33) hold for the NorthSouth extension.

Section C.3 in the Appendix shows the composition of employment in the South, along with global equilibrium conditions. In particular, we present sectoral trade-balance equations and conditions to obtain positive production of the homogeneous good in both countries.

\subsection{Offshoring Costs, Job Flows, and Unemployment}

This section identifies the channels through which offshoring costs affect employment via their impact on trade in differentiated goods. Since we have assumed the fixed costs of offshoring to be zero, below we only consider changes in the variable cost of offshoring, $\lambda$.

\subsubsection{Firm-Level Employment Responses}

From (52) and (53) we obtain that for an existing active firm that does not change its production and export status after a change in the offshoring cost, $\lambda$, its labor-demand response is given by

$$
\zeta_{L(\varphi), \lambda}= \begin{cases}-\frac{\hat{\alpha}}{1-\hat{\alpha}} \zeta_{\hat{\alpha}, \lambda}-(1-\rho) \zeta_{c(\hat{\alpha}), \lambda}-(\sigma-1) \zeta_{\hat{\varphi}_{D}, \lambda} & \text { if } \varphi \in\left[\hat{\varphi}_{D}, \hat{\varphi}_{X}\right) \\ -\frac{\hat{\alpha}}{1-\hat{\alpha}} \zeta_{\hat{\alpha}, \lambda}-(1-\rho) \zeta_{c(\hat{\alpha}), \lambda}-(\sigma-1)\left[\xi_{D} \zeta_{\hat{\varphi}_{D}, \lambda}+\xi_{X} \zeta_{\hat{\varphi}_{X}, \lambda}\right] & \text { if } \varphi \geq \hat{\varphi}_{X},\end{cases}
$$


where each $\zeta \cdot, \lambda$ represents an elasticity with respect to $\lambda, \xi_{D}=\frac{L_{D}(\varphi)}{L(\varphi)}$, and $\xi_{X}=1-\xi_{D} \cdot{ }^{19}$ The following lemma shows the signs of the elasticities in the right-hand side of equation (55).

Lemma 7. $\zeta_{\hat{\alpha}, \lambda}<0, \zeta_{c(\hat{\alpha}), \lambda}>0, \zeta_{\hat{\varphi}_{D}, \lambda}<0, \zeta_{\hat{\varphi}_{X}, \lambda}>0$.

The elasticities $\zeta_{\hat{\alpha}, \lambda}$ and $\zeta_{c(\hat{\alpha}), \lambda}$ are identical to those obtained in the benchmark case, and as before, they give rise to the job-relocation and productivity effects. Note, however, that the coefficient of $\zeta_{c(\hat{\alpha}), \lambda}$ in (55) is $-(1-\rho)$ rather than $-(\sigma-\rho)$ as was the case in equation (34) for the benchmark model. The difference arises because the productivity effect for offshoring firms in the benchmark case has two components: an absolute productivity effect and a relative productivity effect. The latter arises from the fact that the productivity of these firms - and consequently their market share -increases relative to the productivity of non-offshoring firms. Since all firms offshore in the North-South extension, only the absolute productivity effects is present, and therefore, complementarity between inputs $(\rho<1)$ is both necessary and sufficient for the productivity effect to be a source of job creation.

Additionally, we have competition effects in both the domestic and export markets - these effects are driven, respectively, by $\zeta_{\hat{\varphi}_{D}, \lambda}$ and $\zeta_{\hat{\varphi}_{X}, \lambda}$. Note that after a fall in $\lambda$, the competitive environment becomes tougher in the North, $\zeta_{\hat{\varphi}_{D}, \lambda}<0$ : as profit opportunities for Northern firms increase due to the decline in $\lambda$-Northern firms become more competitive relative to Southern firms - entry expands in the North to the point that the free-entry condition is satisfied again. This reduces the residual domestic demand for all Northern firms, and hence, $\hat{\varphi}_{D}$ (the productivity that is needed to exactly meet $f_{D}$ ) increases. After a decline in $\lambda$, the domestic-market competition effect is a source of job losses for both exporting and non-exporting firms. On the other hand, entry of Southern firms decreases - their profit opportunities decline and hence entry must decrease to satisfy the free-entry condition - and therefore, Northern firms face an easier competitive environment in the South. This is reflected in a lower $\hat{\varphi}_{X}\left(\zeta_{\hat{\varphi}_{X}, \lambda}>0\right)$ and a higher residual demand for the good of each Northern exporter. This is the new effect introduced by our extension with trade in differentiated goods. We label it "export-market competition effect" and after a decline in $\lambda$, is a source of job creation for exporting firms.

From (55) note that non-exporting firms experience the same three effects as offshoring firms in the benchmark case: job-relocation, productivity, and (domestic-market) competition effects. ${ }^{20}$

\footnotetext{
${ }^{19} \xi_{D}=\frac{f_{D} /\left(\hat{\varphi}_{D}^{\sigma-1}\right)}{f_{D} /\left(\hat{\varphi}_{D}^{\sigma-1}\right)+f_{X} /\left(\hat{\varphi}_{X}^{\sigma-1}\right)}$, which is the same for every $\varphi \geq \hat{\varphi}_{X}$.

${ }^{20}$ If we assume $f_{o}>0$ (so that an offshoring cutoff productivity level, $\hat{\varphi}_{o}$, exists) and if the fixed costs are such that $\hat{\varphi}_{D}<\hat{\varphi}_{o}<\hat{\varphi}_{X}$ - so that the most productive firms do both exporting and offshoring while the least productive firms do neither - then a decrease in $\lambda$ will have an unambiguous adverse effect on jobs in the non-offshoring Northern firms (those firms with productivities between $\hat{\varphi}_{D}$ and $\hat{\varphi}_{o}$ ), a result that was present in the benchmark case. Other than that, the qualitative results of the North-South model remain unchanged, and therefore, we use the $f_{o}=0$ assumption in the interest of clarity and to focus on the new effects arising due to exporting possibilities.
} 
In addition to these three effects, exporting firms experience the export-market competition effect. The following proposition describes the net effects of a change in the offshoring cost on these firms' employment, along with the net effects on firms that change their production or export status.

\section{Proposition 6. (Offshoring costs and Northern firm-level employment)}

In the North's differentiated-good sector, a decline in $\lambda$ leads to: (i) the death of the least productive non-exporting firms, who then destroy all their jobs; (ii) an ambiguous domestic labor response at surviving non-exporting firms if $\rho<\dot{\rho}$, where $\dot{\rho}<1$, but job destruction otherwise; (iii) an ambiguous domestic labor response at existing exporting firms if $\rho<\ddot{\rho}$, where $\ddot{\rho} \in(1, \sigma)$, but job destruction otherwise; (iv) an ambiguous domestic labor response at existing firms that start exporting.

Part (i) follows from the result that $\hat{\varphi}_{D}$ increases in response to a decline in $\lambda$. Regarding part (ii), recall that for active non-exporting firms, the only source of job creation after a decline in $\lambda$ is the productivity effect when $\rho<1$-input complementarity is necessary but not sufficient for job creation in these firms. As for part (iii), we know that continuing exporting firms have also the export-market competition effect as a source of job creation. This effect dominates the domestic-market competition effect and hence, these firms may create jobs even if $\rho>1$ : input complementarity is neither necessary nor sufficient for job creation in continuing exporting firms after a decline in $\lambda$. Concerning part (iv), note that as $\hat{\varphi}_{X}$ declines some active Northern firms change their status from non-exporting to exporting. From (53) we can see that these firms have a discrete jump in their labor-demand function as they begin to export. These firms may create jobs after a decline in $\lambda$, even if $\rho>\sigma$, because of the job creating force of the export-market competition effect.

We perform a numerical exercise to illustrate our main results. We use the same assumptions and parameter values as in section 3.4, with the exception of the value for $f_{o}$, which is zero in the North-South extension. We also have additional parameters. The total size of the workforce in the South, $\mathbb{L}^{*}$, is set at 15 (identical to the North). As in the North, the sunk entry cost in the South is $f_{E}^{*}=0.8$. The fixed costs of operating domestically and the fixed costs of exporting are identical across countries, $f_{D}=f_{D}^{*}=f_{X}=f_{X}^{*}=0.05$. We set the aggregate productivity parameter for Southern differentiated-good firms, $A^{*}$, to 0.48 . Lastly, we set the iceberg cost for trade in differentiated goods, $\tau$, at 1.7 .

Figure 4 presents $L(\varphi)$, given in (53), for a high offshoring cost $\left(\lambda^{H}=1.8\right)$ and a low offshoring $\operatorname{cost}\left(\lambda^{L}=1.2\right)$ for the cases of perfect input complementarity $(\rho=0)$ and high input substitutability $(\rho=4>\sigma)$. Consistent with the first part of Proposition 6, after a decline in $\lambda$ Figures 4 a and $4 \mathrm{~b}$ show job destruction by death for firms with productivities between $\hat{\varphi}_{D}$ and $\hat{\varphi}_{D}^{\prime}$. For firms 


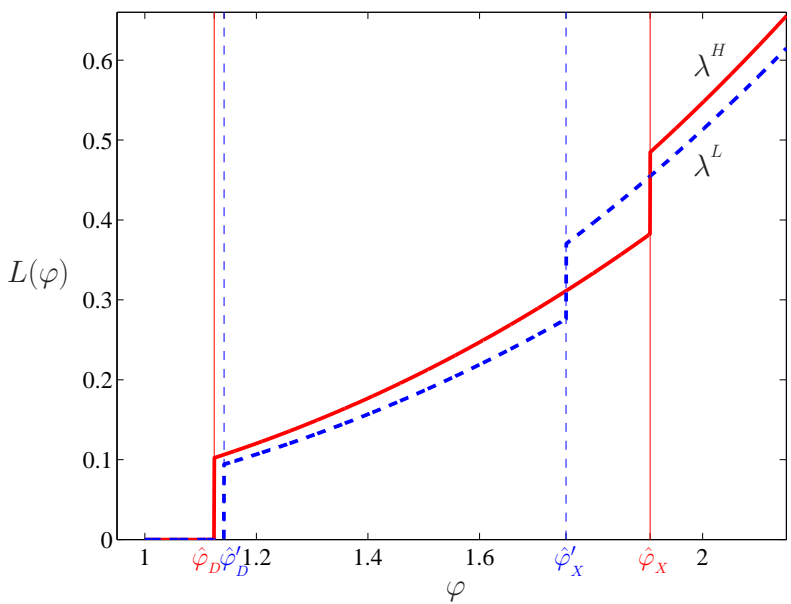

(a) Perfect input complementarity $(\rho=0)$

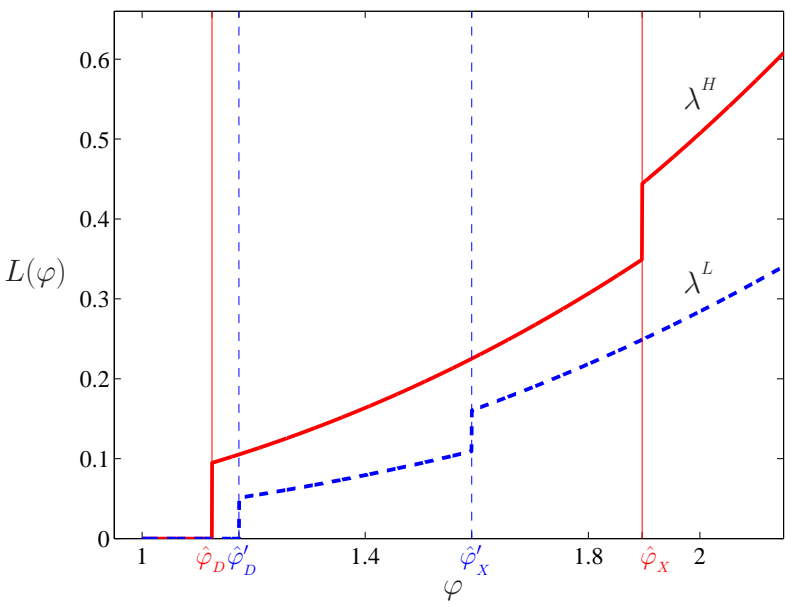

(b) High input substitutability $(\rho=4>\sigma)$

Figure 4: Firm-level demand for Northern labor in sector $Z$ : High offshoring $\operatorname{cost}\left(\lambda^{H}=1.8\right)$ and low offshoring cost $\left(\lambda^{L}=1.2\right)$

with $\varphi \geq \hat{\varphi}_{D}^{\prime}$, Proposition 6 says that the impact of a decline in offshoring costs on employment is ambiguous. In the case of perfect input complementarity (Figure 4a), our numerical example shows job creation for firms that begin to export $\left(\varphi \in\left[\hat{\varphi}_{X}^{\prime}, \hat{\varphi}_{X}\right)\right)$, and job destruction in the other cases. However, with $\rho=0$, the decline in employment is small for both continuing non-exporting firms $\left(\varphi \in\left[\hat{\varphi}_{D}^{\prime}, \hat{\varphi}_{X}^{\prime}\right)\right)$ and continuing exporting firms $\left(\varphi \geq \hat{\varphi}_{X}\right)$. On the other hand, Figure $4 \mathrm{~b}$ shows that for a high elasticity of substitution between inputs, a decrease in $\lambda$ causes a decline in employment for all firms; however, the decline is smaller (in proportion to previous employment) for firms that begin to export. ${ }^{21}$ As in Figure 1, Figures 4a and 4b show the importance of $\rho$ in determining the impact of offshoring on firm-level employment.

\subsubsection{Industry-Level Employment Responses}

Changes in offshoring costs affect the number of firms in the economy, and hence there are also changes at the extensive margin of employment. The following proposition looks into the responses of the different masses of Northern firms when $\lambda$ changes.

Proposition 7. (Offshoring costs, differentiated-good trade, and the masses of firms)

For Northern firms, a decline in the offshoring cost, $\lambda$, causes: (i) increases in the mass of entrants $\left(N_{E}\right)$ and the mass of exporting firms $\left(N_{X}\right)$; (ii) an ambiguous effect on the mass of firms

\footnotetext{
${ }^{21}$ In the comparison of Figures 1a and 4a, note that while a decline in offshoring costs leads to net job creation for the most productive firms in Figure 1a, it leads to net job destruction for the most productive firms in Figure 4a. Recall, however, that Figure 1a was constructed using $f_{o}=0.05$, while we use $f_{o}=0$ in the construction of Figure 4a. For the model without differentiated-good trade with $f_{o}=0$, Figure B.1 in the Appendix shows that a decrease in offshoring costs leads to small job losses even for high productivity firms.
} 
producing for the domestic market $\left(N_{D}\right)$.

In contrast to the ambiguity in the mass of entrants in the benchmark model, the possibility of trade in differentiated goods leads to an increase in $N_{E}$ when $\lambda$ declines; note that there is no change in the cost of trading differentiated goods $(\tau)$. A decline in the offshoring cost increases profit opportunities for Northern firms as they become more competitive relative to Southern firms. This makes entry more attractive in the North. The impact on the mass of Northern firms selling domestically, $N_{D}$, is ambiguous: while an increase in $N_{E}$ tends to raise it, an increase in $\hat{\varphi}_{D}$ reduces it. The mass of Northern exporters, $N_{X}$, increases unambiguously through two channels: first, given the decline in $\hat{\varphi}_{X}$ there is a set of previously domestic-only producers that now become exporters; and second, the set of new entrants (increase in $N_{E}$ ) whose productivities are larger than the new $\hat{\varphi}_{X}$.

Regarding the total employment response in the differentiated-good sector, we take the derivative of $L_{Z}$ in (54) with respect to $\lambda$ to get

$$
\begin{aligned}
\frac{d L_{Z}}{d \lambda}= & \underbrace{\left[-L_{D}\left(\hat{\varphi}_{D}\right) g\left(\hat{\varphi}_{D}\right) \frac{d \hat{\varphi}_{D}}{d \lambda}\right] \frac{N_{E}}{\delta}+\frac{L_{Z}}{N_{E}} \frac{d N_{E}}{d \lambda}}_{\text {Net extensive margin }}+ \\
& \underbrace{\left[\int_{\hat{\varphi}_{D}}^{\infty} \frac{d L_{D}(\varphi)}{d \lambda} g(\varphi) d \varphi+\int_{\hat{\varphi}_{X}}^{\infty} \frac{d L_{X}(\varphi)}{d \lambda} g(\varphi) d \varphi-L_{X}\left(\hat{\varphi}_{X}\right) g\left(\hat{\varphi}_{X}\right) \frac{d \hat{\varphi}_{X}}{d \lambda}\right] \frac{N_{E}}{\delta}}_{\text {Net intensive margin }} .
\end{aligned}
$$

Equation (56) shows two components of the net extensive margin of employment: the change in employment due to the death or birth of firms between the old and new $\hat{\varphi}_{D}$ (because of the effect of $\lambda$ on $\hat{\varphi}_{D}$ ); and the change in employment due to the effect of $\lambda$ on the mass of entrants. On the other hand, the net intensive margin - which looks at domestic employment changes in continuing firms - has three components: the first term shows the change in employment due to production for the Northern market; the second term accounts for the change in employment to produce for the export market from firms that were exporting before (and after) the change in $\lambda$; lastly, the third term shows the change in employment due to production for the export market from firms that change their export status.

\section{Proposition 8. (Offshoring costs and sector-Z's Northern employment)}

For North employment in the differentiated-good sector, a decline in $\lambda$ causes: (i) net job creation at the extensive margin: although there is job destruction due to the death of low-productivity firms, the job creation due to firm entry is larger; (ii) an ambiguous net effect at the intensive margin: there is an ambiguous effect from producing for the Northern market if $\rho<\dot{\rho}<1$ (and job destruction otherwise), an ambiguous effect from producing for the Southern market for continuing 
exporting firms if $\rho<\vec{\rho}$, where $\vec{\rho}>\sigma$ (and job destruction otherwise), and job creation to produce for the Southern market for firms that begin to export; (iii) an ambiguous net effect overall, with net job creation more likely for higher $\eta$ and lower $\rho$.

Part (i) describes entry-driven job creation at the extensive margin after input-trade liberalization. This contrasts with the first part of Proposition 3, in which the effect is ambiguous. Therefore, trade in sector-Z's final goods converts the extensive margin effect of offshoring from ambiguity to net job creation. As discussed earlier, the ambiguity at the intensive margin arises due to the interaction of the job destructing job-relocation and domestic-market competition effects, and the job creating productivity and export-market competition effects. Overall, the final effect of a decline in offshoring costs on Northern employment in the differentiated-good sector is ambiguous, but is more likely to be positive than in the absence of exporting opportunities - for example, in the benchmark case there is net job destruction in sector $Z$ if $\eta \rightarrow 1$ and $\rho \geq 1$, while in this extension the final effect is ambiguous when $\eta \rightarrow 1$ even if $\rho>\sigma$. Thus, extending our model to differentiated-good trade expands the influence of offshoring costs, creating a new channel of action and raising the possibility of overall net job creation in the differentiated-good sector.

For this extension, the effect of a decline in $\lambda$ on the economy-wide unemployment rate follows identically as in section 3.3 - equations (28)-(33) hold and thus, equations (36), (37), and Corollary 1 also hold. Hence, given the determination of sectoral unemployment rates from search friction parameters, a change in $\lambda$ affects $u$ through its impact on the workforce composition.

Let us now highlight with our numerical example the main results for the effects of $\lambda$ on differentiated-good-sector employment. Figure 4 already showed employment responses at the intensive margin along with one of the components of the extensive margin (the job destruction due to firms that die). Figure 4 missed, however, an important component of the extensive margin: the effect of a decline in $\lambda$ on firm entry. As shown in Propositions 7 and 8, a decline in $\lambda$ increases firm entry $\left(N_{E}\right)$ and causes net job creation at the extensive margin.

To see the relevance of this channel on the overall response of Northern employment in the differentiated-good sector, Figure 5 shows the relationship between $\lambda$ and $L_{z}$-from equation (54)for two levels of $\eta$ and three levels of $\rho$ : perfect input complementarity $\left(\rho^{L}=0\right)$, moderate input substitutability $\left(\rho^{M}=2<\sigma\right)$, and high input substitutability $\left(\rho^{H}=4>\sigma\right) .{ }^{22}$ Notice that for $\rho^{L}$, a decline in $\lambda$ is associated with an increase in $L_{z}$ throughout the entire $\lambda$-range even with a low $\eta$. With $\eta=2$, the inverse relationship between $\lambda$ and $L_{Z}$ appears as well in the $\rho^{H}$ case when $\lambda<1.34$. Contrasting Figures 2 and 5, note that the new export-driven channel in this extension

\footnotetext{
${ }^{22}$ The effect of the elasticity of demand for differentiated goods, $\eta$, is the same as in the benchmark case: a higher $\eta$ causes a larger reallocation of expenditure towards differentiated goods when $\lambda$ declines, causing a higher impact on firm entry. As before, $\eta$ does not affect firm-level labor outcomes- $L(\varphi)$ does not depend on $\eta$.
} 


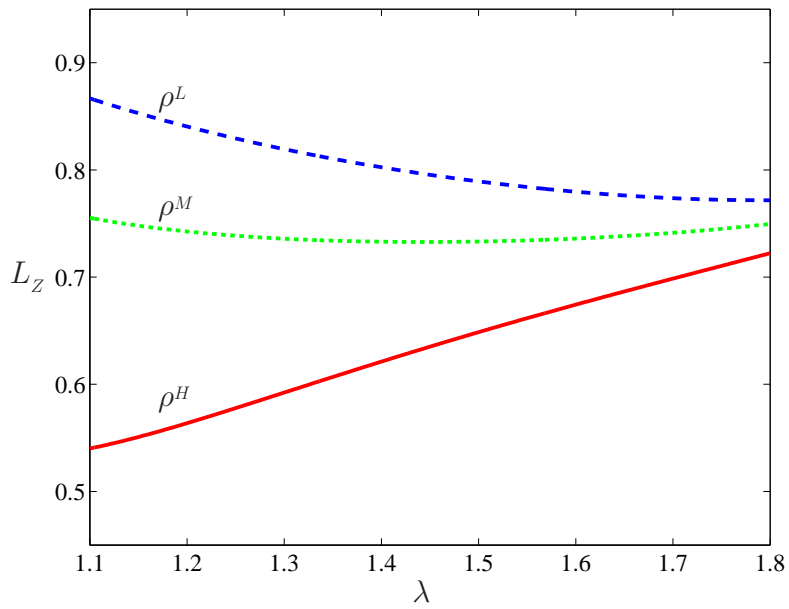

(a) $\eta=1.5$

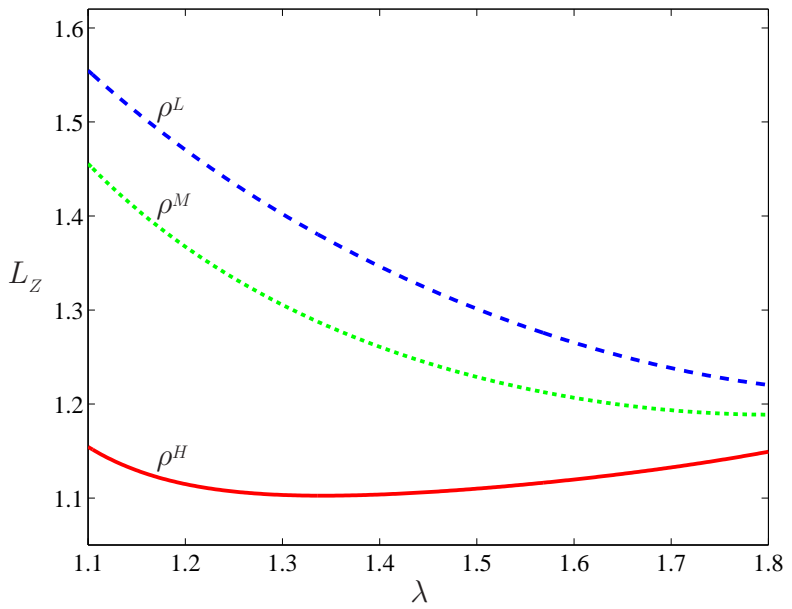

(b) $\eta=2$

Figure 5: Northern employment in sector $Z$ and offshoring costs: Perfect input complementarity $\left(\rho^{L}=0\right)$, moderate input substitutability $\left(\rho^{M}=2<\sigma\right)$, high input substitutability $\left(\rho^{H}=4>\sigma\right)$

makes net job creation in sector $Z$ more likely.

\subsection{Trade Liberalization in Differentiated Goods}

As mentioned earlier, our two-sector structure is similar to Helpman and Itskhoki (2010), except for the differences in (i) the wage-setting approach in the labor market, and (ii) the production function of differentiated-good firms, which in our case allows us to analyze the implications of offshoring. As to the consequences of final-good trade liberalization - which is the only type of trade liberalization that Helpman-Itskhoki consider - the results of our model are the same as in their asymmetric-countries case. ${ }^{23}$ The following lemma shows the signs for the relationship between the cost of trading differentiated goods, $\tau$, and the cutoff productivity levels.

Lemma 8. $\zeta_{\hat{\varphi}_{D}, \tau}<0, \zeta_{\hat{\varphi}_{X}, \tau}>0, \zeta_{\hat{\varphi}_{D}^{*}, \tau}<0, \zeta_{\hat{\varphi}_{X}^{*}, \tau}>0$.

Hence, as pointed out by Melitz (2003), a decline in the cost of trading differentiated goods leads to an increase in the domestic productivity cutoff and a decrease in the exporting cutoff in both countries. Given that $\tau$ does not affect $\hat{w}_{Z}, \hat{\alpha}$, or $c(\hat{\alpha})$, the impact on firm-level Northern employment in sector $Z$ can be easily derived from (52) and (53) as follows:

$$
\zeta_{L(\varphi), \tau}= \begin{cases}-(\sigma-1) \zeta_{\hat{\varphi}_{D}, \tau} & \text { if } \varphi \in\left[\hat{\varphi}_{D}, \hat{\varphi}_{X}\right) \\ -(\sigma-1)\left[\xi_{D} \zeta_{\hat{\varphi}_{D}, \lambda}+\xi_{X} \zeta_{\hat{\varphi}_{X}, \lambda}\right] & \text { if } \varphi \geq \hat{\varphi}_{X} .\end{cases}
$$

\footnotetext{
${ }^{23}$ While asymmetry in the Helpman-Itskhoki setup arises due to differences in labor market frictions across countries, in our setup there is no labor market frictions in the South. Nevertheless, labor market frictions in the North are sufficient to generate differences in the costs of producing differentiated goods across countries and therefore, our results with respect to changes in $\tau$ described below are very similar to those in Helpman and Itskhoki (2010).
} 
It follows from Lemma 8 that non-exporting firms shed jobs - the least productive of them die while the rest destroy jobs by contraction. Continuing exporting firms experience two opposing effects: they experience a contraction from selling to the home market, and an expansion from selling to the foreign market. Also, since $\hat{\varphi}_{X}$ declines, some previously purely-domestic firms start exporting. These firms experience a discrete jump in labor requirements to meet export sales. It is worth contrasting the effects of a decline in $\tau$ (final-good trade liberalization) with those of a decline in $\lambda$ (input trade liberalization): the job-relocation and productivity effects are only present in the latter case.

The impact on overall employment in the differentiated-good sector is given by $\frac{d L_{Z}}{d \tau}$, whose expression is similar to (56) with $d \lambda$ replaced by $d \tau$. As in the Helpman-Itskhoki model, $\tau$ does not affect sectoral unemployment rates and therefore, the response of the economy-wide unemployment rate, $\frac{d u}{d \tau}$, is analogous to (37) with $d \lambda$ replaced by $d \tau$ : similar to the effect of $\lambda, \tau$ affects the unemployment rate only through its impact on the workforce composition, $\frac{\mathbb{L}_{Z}}{\mathbb{L}}$ and $\frac{\mathbb{L}_{H}}{\mathbb{L}}$.

As was also the case in Helpman and Itskhoki (2010), it is difficult to derive analytical results for economy-wide unemployment in the case of two asymmetric countries. We can, however, provide intuitive results that we confirm with numerical illustrations. If the North has a comparative advantage in the differentiated-good sector, then a decline in $\tau$ increases both $L_{Z}$ and the share of the workforce going to the differentiated-good sector in the North. If labor market frictions are higher in the differentiated-good sector so that $u_{Z}>u_{H}$, then a reduction in $\tau$ also leads to an increase in unemployment in the North. Therefore, the effect of $\tau$ on the economy-wide unemployment rate depends on two factors: (ii) whether the North has a comparative advantage in the differentiated-good sector; and (ii) whether the search frictions are higher in the differentiatedgood sector or the homogeneous-good sector. In contrast, the results in the previous sections for a change in offshoring costs obtain irrespective of whether the North has a comparative advantage in the differentiated-good sector as long as the equilibrium is one with incomplete specialization.

Continuing with our numerical example, Figure 6 shows the relationship between $\tau$ and $L_{Z}$ for two levels of offshoring costs $\left(\lambda^{H}=1.8, \lambda^{L}=1.2\right)$, two levels of $\eta(1.5$ and 2$)$, and $\rho=2$. In this example the North has a comparative advantage in producing differentiated goods and therefore, it shows an inverse relationship between $\tau$ and $L_{Z} \cdot{ }^{24}$ Figure 6 also highlights the strong interaction between input trade liberalization and final-good trade liberalization. Note that the effect of finalgood trade liberalization on $L_{z}$ crucially depends on the extent of input trade liberalization: the

\footnotetext{
${ }^{24}$ We choose the value of $A^{*}$ so that the North is always - throughout our assumed range for $\lambda$-a net exporter of differentiated goods. Importantly (and realistically), even if the North is a net exporter of (final) differentiated goods, the North may still run a deficit in its sector- $Z$ 's trade balance. This may be the case because sector $Z$ in the North is a net importer of inputs (due to offshoring), and the value of these net imports may well be larger than the value of its net exports of final goods.
} 


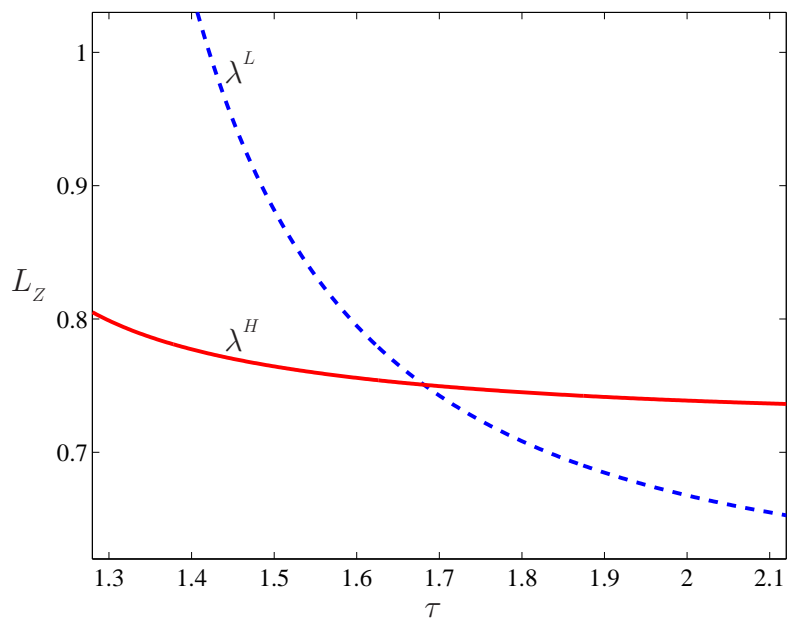

(a) $\eta=1.5$

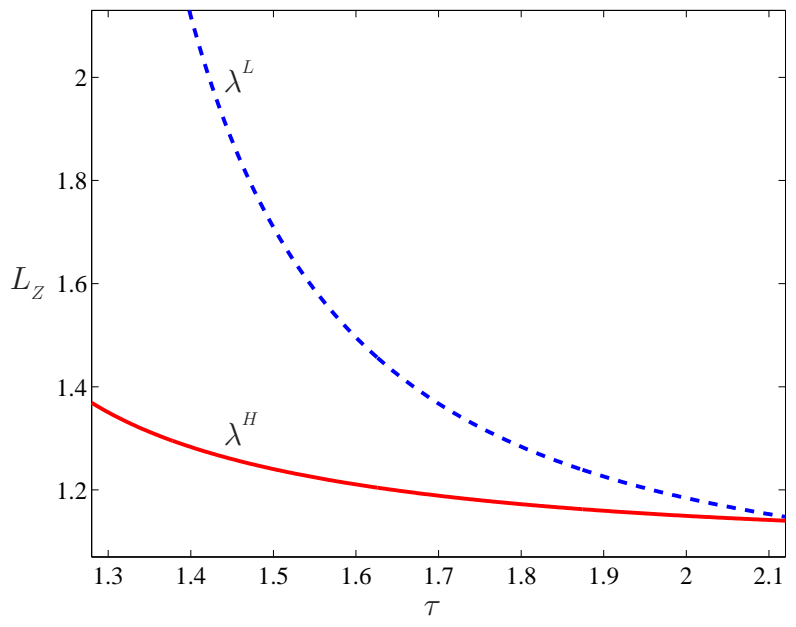

(b) $\eta=2$

Figure 6: Northern employment and final-good trade costs in sector $Z$ : High offshoring $\operatorname{cost}\left(\lambda^{H}=\right.$ 1.8) and low offshoring cost $\left(\lambda^{L}=1.2\right)$

impact of a reduction in $\tau$ on differentiated-good-sector employment is larger the lower the $\lambda$.

Figure $6 \mathrm{a}$ also shows that input trade liberalization and final-good trade liberalization can have opposite effects on $L_{Z}$, and hence different labor market implications. Note that when $\eta=1.5$ and $\tau$ is high (e.g. $\tau=2$ ), the decline in offshoring costs from $\lambda^{H}$ to $\lambda^{L}$ causes net job destruction in the differentiated-good sector. On the other hand, for both values of $\lambda$ a reduction in $\tau$ causes net job creation in the differentiated good sector. This implies that input trade liberalization and final-good trade liberalization can have opposite effects on the economy-wide unemployment rate. Figure 7 highlights this point by showing the relationship between $u$ and $\lambda$, and $u$ and $\tau$, for the cases of perfect input complementarity and high input substitutability. In this numerical example $u_{Z}>u_{H}$-labor market frictions are higher in sector $Z$ - and thus, $L_{Z}$ and $u$ move in the same direction when either $\lambda$ or $\tau$ changes. Note that in the $\rho^{H}$ case, input trade liberalization (a decline in $\lambda$ ) causes a decrease in the economy-wide unemployment rate because workers searching for jobs move from the high-unemployment sector $(Z)$ to the low-unemployment sector $(H)$; the opposite happens with final-good trade liberalization (a decline in $\tau$ ). With perfect input complementarity, both types of liberalization increase the economy-wide unemployment rate. Hence, input trade liberalization is more likely to have the opposite effect on the economy-wide unemployment rate than final-good trade liberalization for lower $\eta$ and higher $\rho$.

Lastly, we can also do comparative statics with respect to the parameters governing search frictions in the North-South extension. The results are similar to those derived in the benchmark model except for the addition of the export competition effect. We present those results in section 


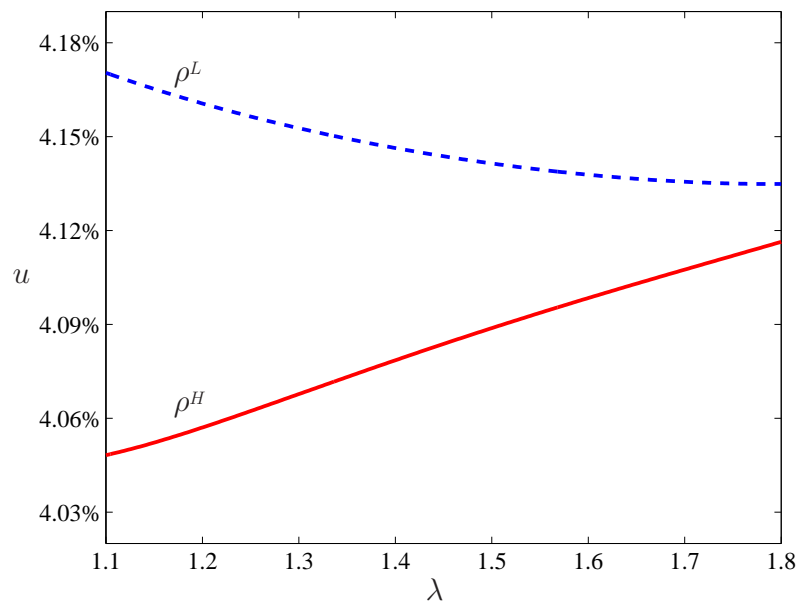

(a) Changes in offshoring cost

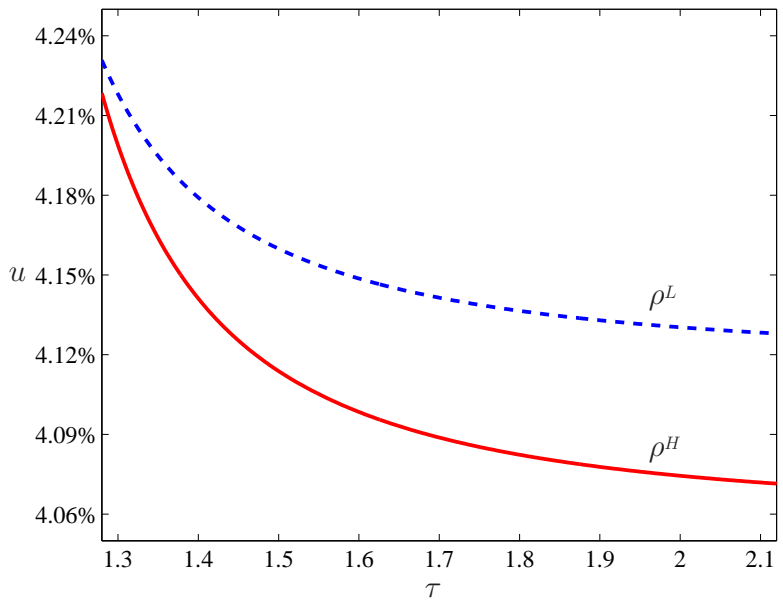

(b) Changes in differentiated-good trade cost

Figure 7: Unemployment rates can move in opposite directions $(\eta=1.5)$ : Perfect input complementarity $\left(\rho^{L}=0\right)$ and high input substitutability $\left(\rho^{H}=4>\sigma\right)$

C.4 in the Appendix.

\section{Conclusions}

We constructed a two-sector theoretical model with labor market frictions to study the impact of offshoring on job flows at the firm and industry levels and on the economy-wide unemployment rate. We identify three channels through which a reduction in the cost of offshoring affects intrafirm and intrasectoral reallocation in the differentiated-good sector: a job-relocation effect, a productivity effect, and a competition effect. After a decline in offshoring costs, the job-relocation and competition effects generate job losses, while the productivity effect can generate job expansions for offshoring firms. The key parameters determining the impact of offshoring on reallocation of jobs at various margins as well as on the economy-wide unemployment are the elasticity of substitution between inputs and the elasticity of demand for differentiated goods.

Allowing differentiated-good producing firms to export creates an additional channel through which a reduction in the cost of offshoring affects jobs and unemployment. Since offshoring lowers the marginal cost of production, firms gain a competitive advantage in the export market, leading to more job creation at both the intensive and the extensive margins. The implications of a reduction in the cost of trading differentiated goods for job flows and unemployment can be very different from those of a reduction in the offshoring cost. As well, the two trading costs interact in significant ways. The impact of a decrease in the cost of trading differentiated goods on job flows is larger the smaller the offshoring cost. 


\section{References}

Amiti, M., And J. Konings (2007): "Trade Liberalization, Intermediate Inputs, and Productivity: Evidence from Indonesia," American Economic Review, 97(5), 1611-1638.

Amiti, M., And S.-J. Wei (2005): "Fear of Service Outsourcing: Is It Justified?," Economic Policy, 20(42), 308-347.

(2009): "Service Offshoring and Productivity: Evidence from the US," The World Economy, 32(2), 203-220.

Antràs, P., And E. Helpman (2004): "Global Sourcing," Journal of Political Economy, 112(3), $552-580$.

Bernard, A. B., J. B. Jensen, S. J. Redding, and P. K. Schott (2007): "Firms in International Trade," Journal of Economic Perspectives, 21(3), 105-130.

Bernard, A. B., J. B. Jensen, and P. K. Schott (2009): "Importers, Exporters and Multinationals: A Portrait of Firms in the U.S. that Trade Goods," in Producer Dynamics: New Evidence from Micro Data, pp. 513-552. University of Chicago Press.

Bernard, A. B., S. J. Redding, and P. K. Schott (2007): "Comparative Advantage and Heterogeneous Firms," Review of Economic Studies, 74(1), 31-66.

Biscourp, P., and F. Kramarz (2007): "Employment, Skill Structure and International Trade: Firm-Level Evidence for France," Journal of International Economics, 72(1), 22-51.

Davidson, C., And S. J. Matusz (2004): International Trade and Labor Markets: Theory, Evidence, and Policy Implications. W. E. Upjohn Institute.

(2005): "Trade and Turnover: Theory and Evidence," Review of International Economics, $13(5), 861-880$.

Davidson, C., S. J. Matusz, and A. Shevchenko (2008): "Outsourcing Peter To Pay Paul: High-Skill Expectations And Low-Skill Wages With Imperfect Labor Markets," Macroeconomic Dynamics, 12(4), 463-479.

Egger, H., U. Kreickemeier, and J. Wrona (2013): "Offshoring Domestic Jobs," CESifo Working Paper Series 4083, CESifo Group Munich.

Felbermayr, G., J. Prat, and H.-J. Schmerer (2011): "Globalization and labor market outcomes: Wage bargaining, search frictions, and firm heterogeneity," Journal of Economic Theory, 146(1), 39-73.

Goldberg, P. K., A. K. Khandelwal, N. Pavcnik, and P. Topalova (2010): "Imported Intermediate Inputs and Domestic Product Growth: Evidence from India," Quarterly Journal of Economics, 125(4), 1727-1767.

Gopinath, G., and B. Neiman (2013): "Trade Adjustment and Productivity During Large Crises," American Economic Review, forthcoming.

Görg, H. (2011): "Globalization, Offshoring and Jobs," in Making Globalization Socially Sustainable, ed. by M. Bacchetta, and M. Jansen. World Trade Organization. 
Görg, H., and A. Hanley (2005): "Labour Demand Effects of International Outsourcing: Evidence from Plant-Level Data," International Review of Economics 83 Finance, 14(3), 365-376.

Grossman, G. M., and E. Rossi-Hansberg (2008): "Trading Tasks: A Simple Theory of Offshoring," American Economic Review, 98(5), 1978-97.

Harrison, A., and M. McMillan (2011): "Offshoring Jobs? Multinationals and U.S. Manufacturing Employment," Review of Economics and Statistics, 93(3), 857-875.

Helpman, E., and O. Itskhoki (2010): "Labour Market Rigidities, Trade and Unemployment," Review of Economic Studies, 77(3), 1100-1137.

Hijzen, A., And P. Swaim (2007): "Does Offshoring Reduce Industry Employment?," National Institute Economic Review, 201(1), 86-96.

Hummels, D., R. Jorgensen, J. R. Munch, and C. Xiang (2011): "The Wage Effects of Offshoring: Evidence from Danish Matched Worker-Firm Data," Working Paper 17496, National Bureau of Economic Research.

Ibsen, R., F. WARzynski, and N. Westergard-Nielsen (2010): "Employment Growth and International Trade: A Small Open Economy Perspective," Aarhus School of Business, Department of Economics.

Melitz, M. J. (2003): "The Impact of Trade on Intra-Industry Reallocations and Aggregate Industry Productivity," Econometrica, 71(6), 1695-1725.

Mitra, D., And P. Ranjan (2010): "Offshoring and Unemployment: The Role of Search Frictions Labor Mobility," Journal of International Economics, 81(2), 219-229.

Moen, E. R. (1997): "Competitive Search Equilibrium," Journal of Political Economy, 105(2), $385-411$.

Moore, M. P., And P. Ranjan (2005): "Globalisation vs Skill-Biased Technological Change: Implications for Unemployment and Wage Inequality," Economic Journal, 115(503), 391-422.

Ranjan, P. (2013): "Offshoring, Unemployment, and Wages: The Role of Labor Market Institutions," Journal of International Economics, 89(1), 172-186.

Shimer, R. (1996): "Contracts in a Frictional Labor Market," manuscript, Massachusetts Institute of Technology.

Stole, L. A., And J. Zwiebel (1996): "Intra-Firm Bargaining under Non-Binding Contracts," Review of Economic Studies, 63(3), 375-410.

Topalova, P., and A. Khandelwal (2011): "Trade Liberalization and Firm Productivity: The Case of India," Review of Economics and Statistics, 93(3), 995-1009.

Wagner, J. (2011): "Offshoring and Firm Performance: Self-Selection, Effects on Performance, or Both?," Review of World Economics, 147(2), 217-247. 